Using Web 2.0 to collaborate with stakeholders: An exploratory study of central government organisations in New Zealand

by

Anand Kochunny

Submitted to the School of Information Management,

Victoria University of Wellington

in partial fulfilment of the requirements for the degree of

Master of Library and Information Studies 


\section{Abstract}

Web 2.0 tools such as wikis appear to hold promise for collaboration between organisations and their stakeholders. Government organisations in certain countries have only started making use of wikis to collaborate with their stakeholders. This phenomenological study examines the experience of select officials in two central government organisations in New Zealand who have been instrumental in deploying wikis to collaborate with their stakeholders. Three wikis are the subject of this study, and the officials are interviewed to gain an understanding of: (a) the circumstances under which decisions were taken to deploy wikis; (b) the benefits that might accrue to the organisations from using wikis; (c) the strategies they have used to maximise the benefits of using wikis; (d) the pitfalls that they have faced in deploying the wikis, and the manner in which they have overcome these pitfalls. The experiences of these officials are distilled to share their insights with others who may wish to follow their lead.

[158 words]

Keywords: Web 2.0; wiki; government, stakeholder; collaboration; collaborative software; social software; read/write Web. 


\section{Acknowledgements}

This study has been possible due to the efforts of many:

- a trio of kind but determined ladies who have kept me going even when the tunnel seemed never-ending - my wife, my supervisor, and my former manager;

- the respondents who participated in this study - you gave your time so generously and gladly that I owed it to you to complete this study;

- my colleagues at my workplace, who have been there to help and support me all through this programme, with words of encouragement and acts of concern;

- Bethany and Tony at $360 \mathrm{Hubs,}$ who stepped in at the eleventh hour like an answer to a prayer;

- my son, who has been as patient as an angel through most of his young life;

- and Sam, who was there at the beginning, and at the end.

Thank you, all — I couldn't have done it without you! 
VICTORIA UNIVERSITY OF WELLINGTON

School of Information Management

Master of Library \& Information Studies

IMPORTANT DISCLAIMER

with respect to a MLIS Research Project (INFO 580)

\title{
Using Web 2.0 to collaborate with stakeholders: An exploratory study of central government organisations in New Zealand
}

\section{(hereafter referred to as 'The MLIS Research Project')}

\author{
being undertaken by
}

\section{Anand Kochunny}

in partial fulfilment of the requirements of the degree of Master of Library and Information Studies,

School of and Information Management, Victoria University of Wellington.

\section{Topic Commencement: January 2008}

1. Victoria University of Wellington and its Council, its members, staff, employees, students and agents undertake no duty of care in contract, tort, or otherwise, to users (whether direct or indirect) of the MLIS Research Project and make no warranties or representations of any kind whatsoever in relation to any of its contents.

2. The MLIS Research Project is only made available on the basis that all users of it, whether direct or indirect, must take appropriate legal or other expert advice in relation to their own circumstances and must rely solely on their own judgement and such legal or other expert advice.

3. Under no circumstances will Victoria University of Wellington and its Council, its members, staff, employees, students or agents be liable in any way whatsoever, whether in contract, tort (including negligence), for breach of any statutory or regulatory duty (to the fullest extent permissible by law), or otherwise, to any user (whether direct or indirect) of the MLIS Research Project for any loss or damage whatsoever arising directly or indirectly as a result of the use in any way of the MLIS Research Project.

4. Each exclusion in the clauses of this disclaimer and each protection given by it is to be construed as a separate exclusion applying and surviving even if for any reason any of the exclusions or protections are held inapplicable in any circumstance. 


\section{Table of Contents}

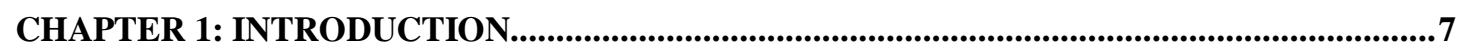

CHAPTER 2: THE RESEARCH PROBLEM.....................................................................................10

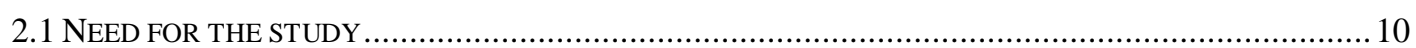

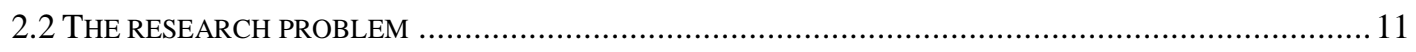

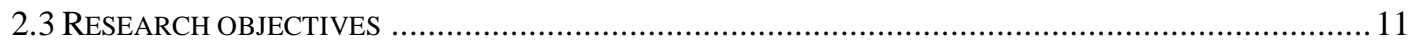

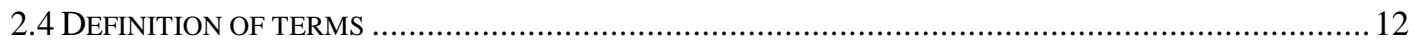

CHAPTER 3: THE REVIEW OF THE LITERATURE .............................................................14

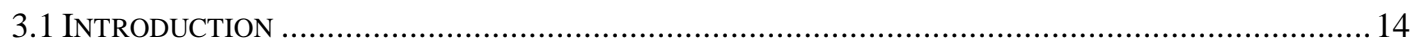

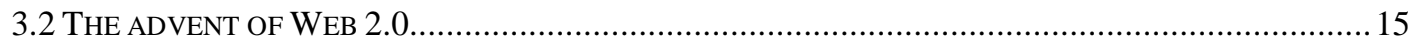

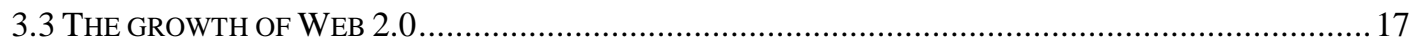

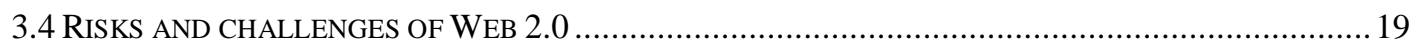

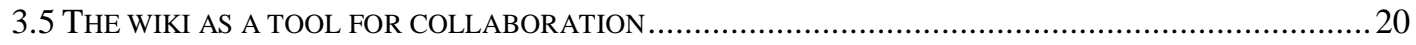

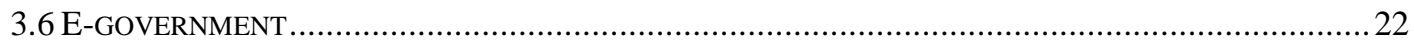

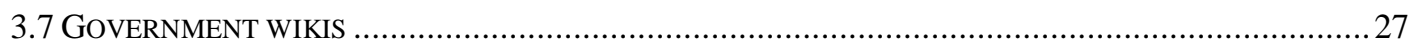

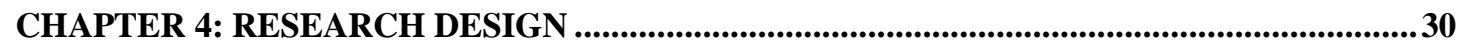

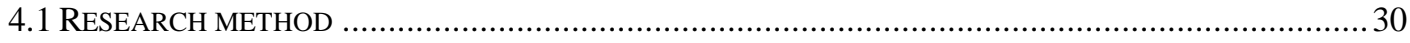

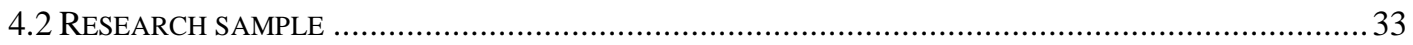

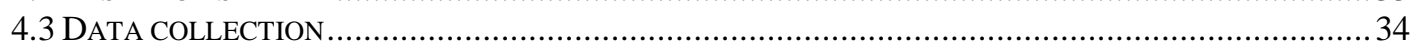

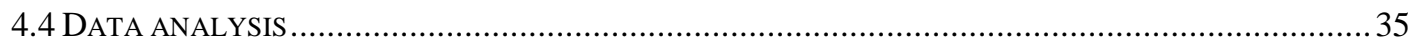

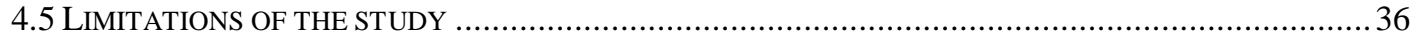

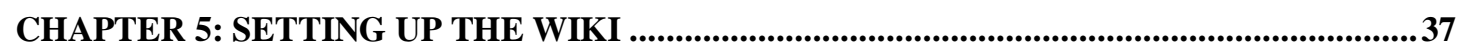

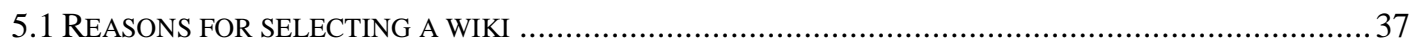

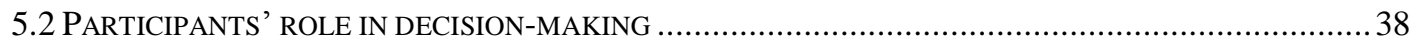

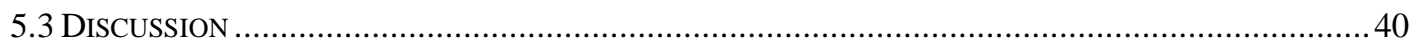

CHAPTER 6: WIKI — BENEFITS AND STRATEGIES ...................................................42

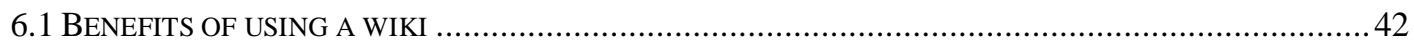

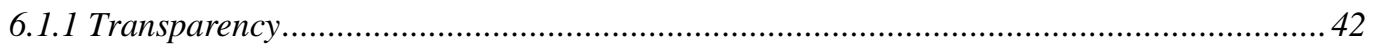

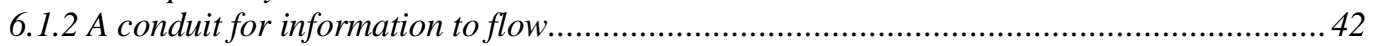

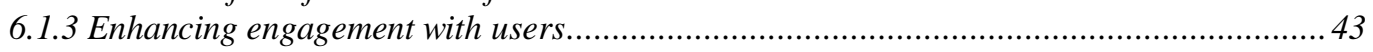

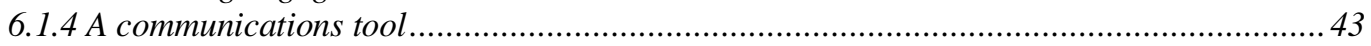

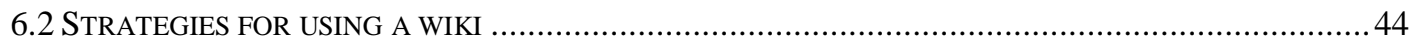

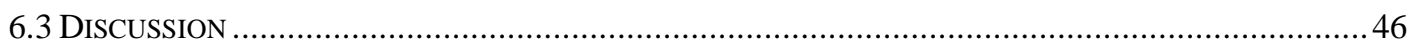

CHAPTER 7: OVERCOMING TECHNOLOGICAL CONSTRAINTS .....................................49

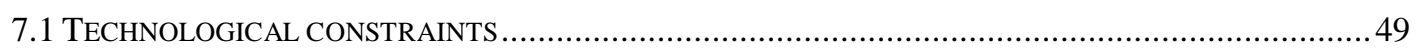

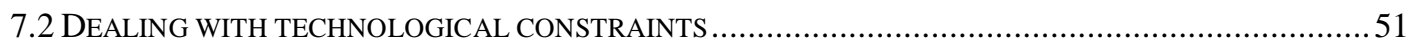

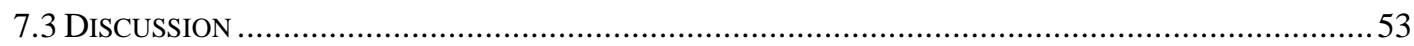

CHAPTER 8: PITFALLS AND RISKS IN WIKI USAGE ............................................................56

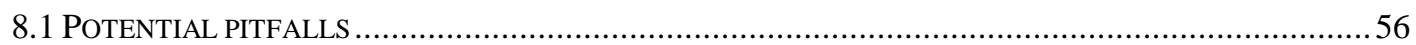

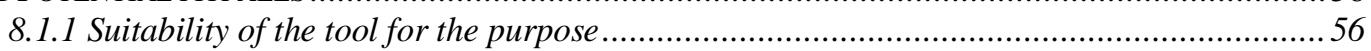

8.1.2 Resource-intensive nature of Web 2.0 applications ....................................................5

8.1.3 Dealing with vandalism and legal liability ......................................................................5 58

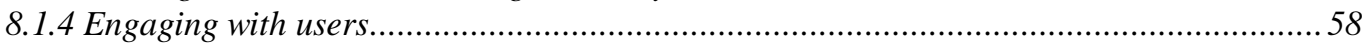

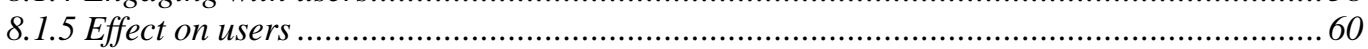

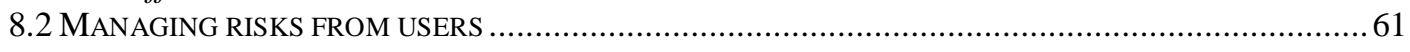

8.2.1 Access to the wiki....................................................................................................... 61 


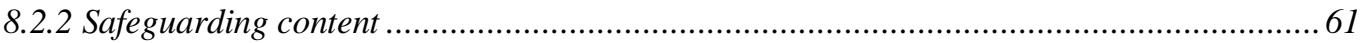

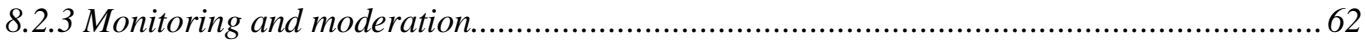

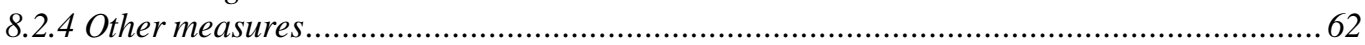

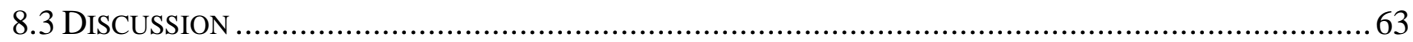

CHAPTER 9: WIKI USAGE: BARRIERS AND FACILITATION .................................................66

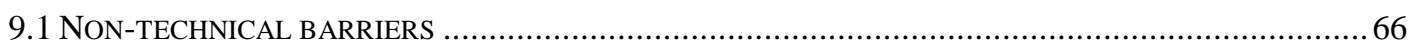

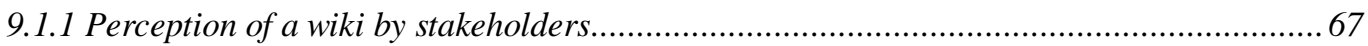

9.1.2 Organisation and management of information............................................................. 67

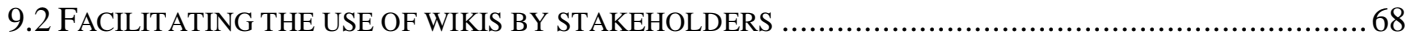

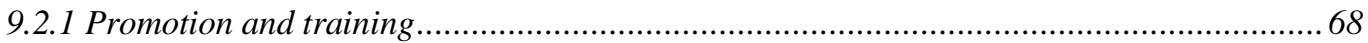

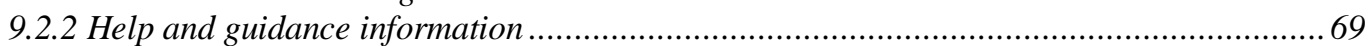

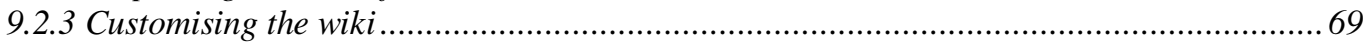

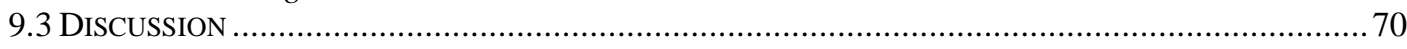

CHAPTER 10: USING WIKIS: OTHER ISSUES ................................................................

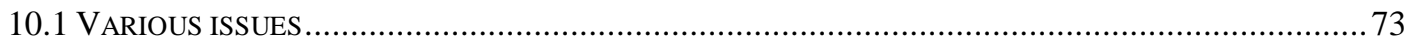

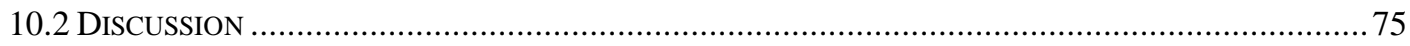

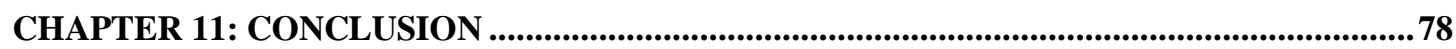

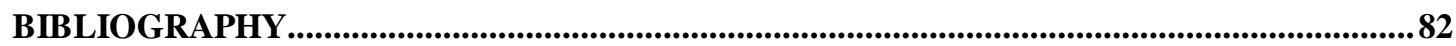

APPENDIX A: SAMPLE PERMISSION LETTER .......................................................................87

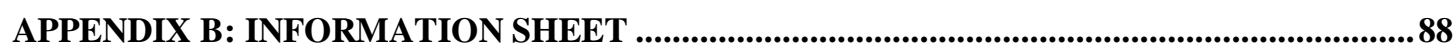

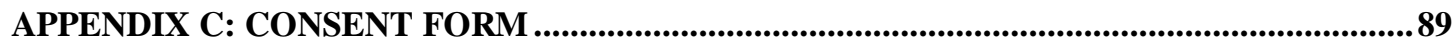

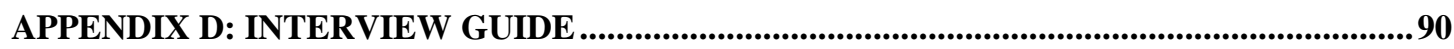

APPENDIX E: SAMPLE OF PRIMARY EVIDENCE COLLECTED ..........................................91 


\section{Chapter 1: Introduction}

2004 was significant in the history of e-government in New Zealand. At the beginning of that year, the E-Government Unit - which had been established as a part of New Zealand's State Services Commission in July 2000 - began its "first comprehensive assessment of the government's online presence" (Millar, 2004). This review led to the adoption of the following goals:

- Convenience and satisfaction: People will be able to find details of a wide range of government services on the Internet

- Integration and efficiency: Agencies will begin to integrate services through use of common e-government "foundations" (technology, standards and policies). Agencies will be more citizen- and results-oriented in the way they design themselves.

- Participation: Government agencies will be making better use of the Internet to inform the public of what is happening in government, and of opportunities to be involved in government processes. Agencies will be learning ways to make use of the Internet to consult people about policy development, and service design and delivery. (State Services Commission, 2004)

It is the last sentence in the paragraph above that gives rise to my study. Even before the dawn of the new millennium, the World Wide Web had evolved from static web pages that pushed content to the public to websites such as Wikipedia, which are created from user-generated content and attract mushrooming communities of users around them. This phenomenon has led to the coinage of a new term - Web 2.0. This term is used to refer to a wide variety of Web-based software applications and 
services that have a common theme - their content comes from their community of users, and they enable members of their community to interact among themselves. Such software applications are therefore also referred to as 'social software'.

As it often happens with the introduction of new technology, Web 2.0 applications have become immensely popular with younger members of society. It would be fair to say that this success is driven by their adoption by the youth, for whom selfexpression and networking with peers are powerful motivational forces. One of the features of Web 2.0 applications that has made them attractive to governments is that they make it easier for people to work collaboratively.

Governments, being cautious by nature, tend to take a wait-and-watch approach to new trends that alter the social fabric before deciding on their adoption. However, governments also need to be in touch with citizens. When they are faced with the fact that a new technology is fast becoming a means of communication for a significant number of citizens, governments realise the need to adopt it — or risk being unheard by tomorrow's decision-makers.

A final point that needs to be mentioned here is that Web 2.0 applications have become popular not simply because they allow people to communicate easily, but also because they enable people to collaborate with convenience. While this feature meets the social needs of their communities of users, some governments have realised that they can use this feature for their officials to interact and communicate with their stakeholders. My study explores the steps that certain New Zealand government 
organisations have taken in using Web 2.0 tools to communicate and collaborate with their stakeholders. 


\section{Chapter 2: The Research Problem}

\subsection{Need for the study}

Enabling Transformation, the third update to New Zealand's E-Government Strategy, mentions the provision of collaborative tools in its list of planned activities:

State servants are given collaborative tools to enhance communication and professional development, and allow them to work and share in cross-agency projects and activities. (State Services Commission, 2006)

Before deploying such tools, it would be useful to find out how they can be applied to the work of New Zealand government organisations. It would help to understand how government organisations can make the best use of these tools, how they can avoid some of the pitfalls they might encounter in deploying such tools, and how they can persuade their stakeholders to make use of these tools to work collaboratively.

While a review of the literature on the use of Web 2.0 applications by government organisations finds a few instances of work focusing on particular applications such as wikis, little work has been published that investigates the use of such applications by government organisations. Most government organisations in New Zealand are yet to use Web 2.0 applications to collaborate with their stakeholders, and my study focuses on those that have taken the lead in doing so. 


\subsection{The research problem}

My study examines the experience of some of New Zealand's central government organisations in using Web 2.0 applications to collaborate with their stakeholders. To do so, my study focuses on the following questions:

(a) Why should a government organisation use a Web 2.0 tool to collaborate with its stakeholders?

(b) How can a government organisation make the best possible use of a Web 2.0 tool to collaborate with its stakeholders?

(c) How can a government organisation overcome potential hazards that it might face in using a Web 2.0 tool to collaborate with its stakeholders?

\subsection{Research objectives}

The following objectives have guided the direction of my study:

(i) To understand the circumstances under which a government organisation might consider using a Web 2.0 tool to collaborate with its stakeholders;

(ii) To gather information about the benefits that might accrue to a government organisation from using a Web 2.0 tool to collaborate with its stakeholders; 
(iii) To examine the strategies that a government organisation might deploy to harness the benefits of using a Web 2.0 tool to collaborate with its stakeholders;

(iv) To identify the barriers (both technological and non-technological) that a management organisation might encounter in using a Web 2.0 tool to collaborate with its stakeholders;

(v) To identify potential pitfalls (including risks from users) that a government organisation might face in using a Web 2.0 tool to collaborate with its stakeholders;

(vi) To gather information about the measures that a government organisation might take to help its stakeholders make the best use of its Web 2.0 tool.

\subsection{Definition of terms}

Central Government: The legislative and executive arms of Government, i.e. Parliament and its offices, Cabinet, and the State Services. Those elected in triennial general elections and the institutions directly accountable to them, whose authority covers the entire country. As distinct from 'local government'. (State Services Commission; n.d.)

It is worth noting here that the terms 'organisation', 'agency', and 'department' will be used interchangeably throughout this study to refer to any autonomous entity with its own chief executive - that is an organ of New Zealand's central government. The terms 'public sector', 'public service' and 'state sector' will also be used 
interchangeably in my study to refer to the group of organisations that make up New Zealand's central government.

Stakeholder: The New Zealand government does not have a formal definition for the term 'stakeholder'. However, this term is defined by the Oxford English Dictionary as "a person, company, etc., with a concern or (esp. financial) interest in ensuring the success of an organization, business, system, etc." (Oxford English Dictionary, 2009).

For a New Zealand government agency, stakeholders would therefore include Vote Ministers/ Associate Ministers for that particular area of governance (e.g., transport); other New Zealand government organisations that it needs to work with to achieve joint outcomes; individuals/ organisations that can contribute to a particular project; and also members of the New Zealand public.

Web 2.0: Web 2.0 is the network as platform, spanning all connected devices; Web 2.0 applications are those that make the most of the intrinsic advantages of that platform: delivering software as a continually-updated service that gets better the more people use it, consuming and remixing data from multiple sources, including individual users, while providing their own data and services in a form that allows remixing by others, creating network effects through an "architecture of participation," and going beyond the page metaphor of Web 1.0 to deliver rich user experiences.

(O’Reilly, 2005). 


\section{Chapter 3: The Review of the Literature}

\subsection{Introduction}

In the course of this literature review, I have attempted to find a relationship between the utility of Web 2.0 tools on the one hand — the wiki, in particular — and the role of government, on the other. Ultimately, this review of the literature seeks to find grounds for government organisations to use Web 2.0 tools such as the wiki to collaborate with their stakeholders.

The search terms I have used are: Web 2.0, read/ write Web, wiki(s), social software, collaborative software, social media, social networks, government, and e-government. I have used a combination of these terms while searching library catalogues and bibliographic databases, looking for a link between government activity and Web 2.0 tools. I have used the search engines of abstracting and indexing databases such as LISA (Library and Information Science Abstracts), and full-text databases such as Emerald. I have also used Google while conducting my search. When I have found instances of specific government wikis referred to in the literature, I have used both Google and Wikipedia to track them down.

There is a paucity of literature available on the use of wikis by government organisations, which is not surprising when one considers that the idea is still at a nascent stage. Few government organisations have actually ventured to try using wikis, and even fewer have used wikis to collaborate with external stakeholders. Understandably, organisations would want to experiment with a wiki internally and come to grips with it before using it to collaborate with external stakeholders. I have 
therefore looked at the literature on the wider field of social software, and the literature on e-government to provide a basis for this study.

This literature review begins by asking the question: what is Web 2.0? It balances the opinion of the inventor of the World Wide Web (who is not impressed by the term Web 2.0) against the opinion of two academics (who justify the use of the term). Next, this review looks at the growing influence of Web 2.0 tools on our lives particularly in our working environment. It also considers some of the risks and challenges posed by Web 2.0 applications.

Moving on from Web 2.0 to wikis, this review then dwells on the strengths and potential pitfalls of wikis, and touches on the use that some organisations have found for wikis, as well as some best practice tips on implementing an intranet wiki. The review then examines changes to government's role in society — and consequently changes to the part played by government employees in their interaction with members of the public that have been brought about by technological advances such as e-government.

Finally, this review looks at some examples of wikis that are being used by government organisations overseas to collaborate with their stakeholders, and considers some of the barriers to the use of wikis in the public sector.

\subsection{The advent of Web 2.0}

Is there any such thing as 'Web 2.0'? Not according to Sir Tim Berners-Lee, inventor of the World Wide Web, who considers Web 2.0 to be "a piece of jargon" 
(Laningham, 2006). Sir Tim feels that the fundamentals of Web 2.0 applications have not sufficiently changed from Web 1.0 to merit a different name.

However, Vossen and Hagemann explain how a number of forces - commercial, technological and social — are responsible for the evolution of the World Wide Web from 'Version 1.0' to 'Version 2.0'. (Vossen and Hagemann, 2007). Vossen and Hagemann contend that the essential characteristics of Web 2.0 applications include the following dimensions:

- Data: Web 2.0 applications integrate data from various sources to create new information or add value to existing information;

- Functionality: Web 2.0 applications combine existing applications to create Rich Internet Applications on the Web that would have been available on standalone computers in earlier times;

- Socialisation: Web 2.0 applications enable users to share their information with others online — be they friends, a community of like-minded souls, or the public at large.

It would be fair to say that while Web 1.0 applications enabled information to be only 'pushed' to passive users, Web 2.0 applications have enabled users to actively interact with the information by adding to it, editing it, or combining it with other information, and sharing their work with others who have similar interests. Hence, Web 2.0 is also referred to as the 'read/ write Web', and Web 2.0 applications are also called 'social software' or 'collaborative software'. 


\subsection{The growth of Web 2.0}

In January 2009, the Pew Internet and American Life Project reported the results of its December 2008 tracking survey on adults and social network websites. This survey found that in the four years from 2005 to 2009, the number of American adult Internet users who had a profile on a social network site had increased more than four-fold from $8 \%$ to $35 \%$ (Lenhart, 2009). It would seem that social software is on its way to becoming a part of our lives.

Niall Cook (2008) extends the reach of social software in our lives by considering how these applications may transform the way we work. Cook proposes a $4 \mathrm{Cs}$ approach to classifying social software, on the basis of the primary functions of the tools:

- Communication, e.g., discussion fora, blogs, instant messaging, virtual worlds;

- Co-operation, e.g., image/ video sharing, social bookmarking, social cataloguing;

- Collaboration, e.g., wikis, human-based/ evolutionary computation;

- Connection, e.g., tagging, syndication, mashups.

Cook goes on to discuss factors responsible for the success or failure of social software in enterprises, and provides advice on how organisations may adopt and implement social software in their work. 
Melcrum, a company that specialises in internal communication for enterprises, has compiled a checklist of the following top 10 issues that an organisation should consider while developing its social media strategy (Manchester, 2007):

1. Assess your organisation's cultural readiness

2. Focus on the people, not the technology

3. Think about the business purpose of the tools

4. Make sure you grasp the difference between traditional and social media

5. Prepare to relinquish control and share the process

6. Be experimental and involve employees

7. Clarify what employees can and can't do

8. Take a hands-off approach to marketing the tools

9. Work with what you've got and integrate new tools

10. Don't obsess about the numbers

The following image from $360 \mathrm{Hubs}$ illustrates how a variety of social software applications can find a place in an organisation's business: 


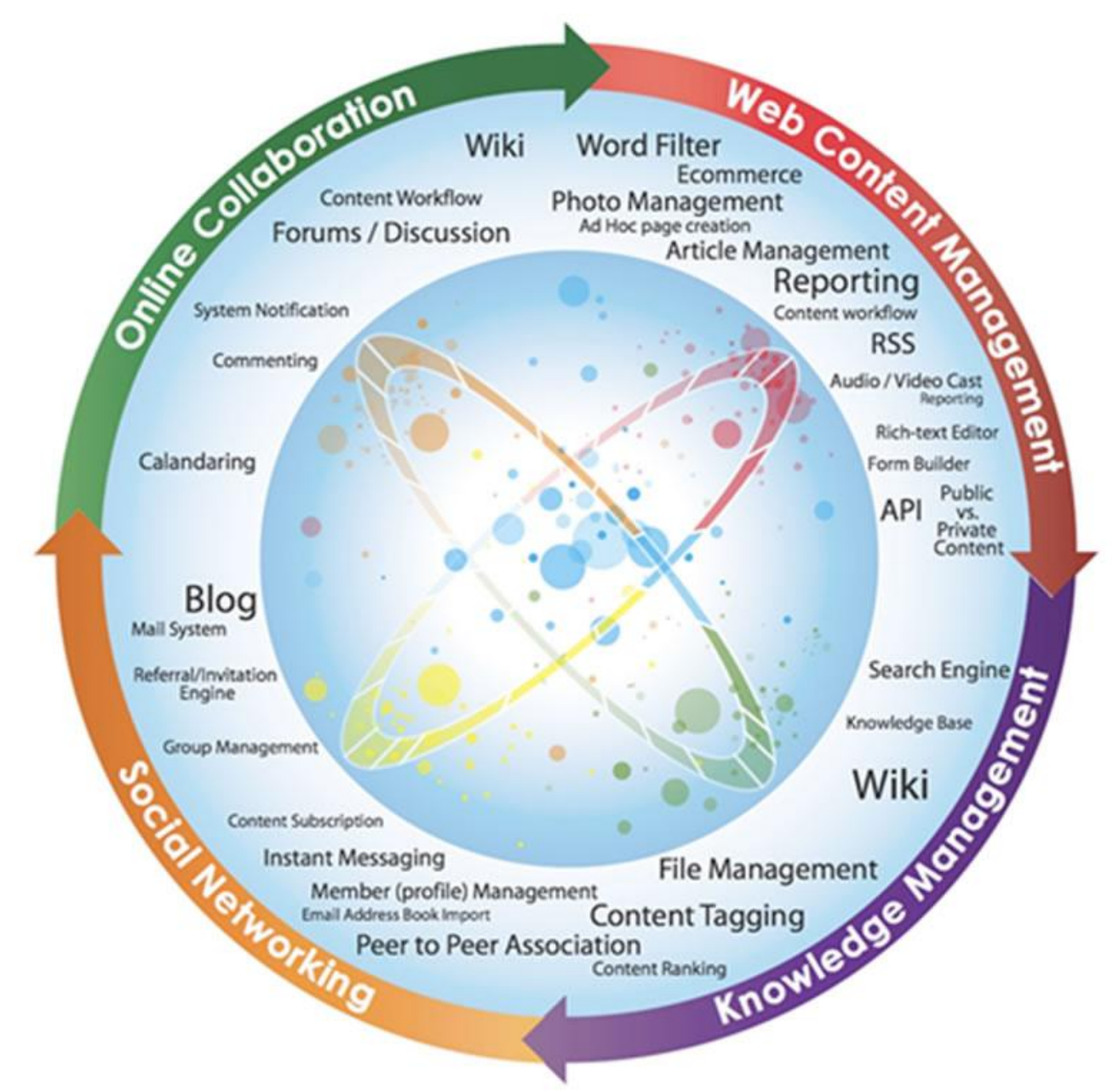

360hubs Reserves All Rights to the Above Image and is the Rightful Owner Copyright 2005, 2006, 2007, 2008, 2009

\section{6 hubs}

www.360hubs.com

\subsection{Risks and challenges of Web 2.0}

There is concern about the security of Web 2.0 applications. It appears that there are two main kinds of web attacks which are alarming security specialists: cross-site scripting attacks, and cross-site request forgeries (Is Web 2.0 safe? 2007) A cross-site scripting attack results in a user's browser being compromised to run malicious script(s), while a cross-site request forgery results in a website being deceived into thinking that it is sending data to a legitimate user. With the growth in the adoption of widgets by social software users (small programs created by other users), the danger 
of attacks on users of Web 2.0 software can only increase. Given that Web 2.0 sites usually store personal information about users, it leads to the conclusion that identity theft is but a short step away, as Symantec's $13^{\text {th }}$ Internet Security Threat Report indicates (Symantec, 2008).

Dellow (2008) considers the challenges posed by Web 2.0 applications, and highlights the following issues:

- Managing the movement of large volumes of data across the Web as users become active creators of content and combine data from various streams to generate rich media

- Weighing the philosophy of trust in users that is at the core of Web 2.0 applications against the need for information security

- Ensuring that users behave appropriately while online

- Ownership of an individual's social network created at work — does it lie with the individual, the individual's employer, or the organisation that provides the social network service

- Whether it is appropriate for a government to use Web 2.0 services if the service provider stores data in another country

\subsection{The wiki as a tool for collaboration}

Of the various Web 2.0 tools, the wiki stands out as one that can be used by different parties to collaborate in creating content. The Oxford English Dictionary defines a wiki as "a type of web page designed so that its content can be edited by anyone who accesses it, using a simplified markup language." (Oxford English Dictionary Online, 2009). 
Tapscott and Williams (2006) provide examples of the impact that social software have had on business enterprises while discussing how collaboration by the masses has altered the business environment. They mention the instance of an investment bank in Europe where principal users of the company's wiki have reported a 75\% decrease in the number of emails, and a $50 \%$ reduction in the time spent in meetings.

Klobas (2006) regards the following as the strengths of a wiki:

- As a resource that is developed through the contributions of many individuals, a wiki is expected to be more accurate, and have greater reach and depth, in comparison to a work of single authorship. This premise is based on the assumption that the contributors to a wiki are experts in their field.

- A wiki can be created and edited swiftly and easily, resulting in its information being more current than a traditionally published document.

- A wiki can be accessed by any computer that is connected to the Web.

- A wiki allows users to examine how its subject matter has evolved over time through the use of its revision-tracking facility.

Klobas then goes on to discuss some of the potential pitfalls of wikis, such as:

- A wiki depends on people continuing to contribute to it, in order to remain current.

- A wiki requires proper administration so that closed pages are spotted, and pages are locked and date-stamped for historical purposes.

- An open wiki can be compromised by web bots 
- A wiki may present navigational difficulties to users in the absence of a contents list, or if it has a poor search engine.

Jespersen and Boye (2008) talk about some of the different ways in which wikis have been used in enterprises:

- Encyclopaedia, e.g., information resource for new employees

- Manuals and guidelines

- Opening for all to edit on some existing intranet pages

- Project collaboration, e.g., innovation projects or on daily tasks

- Project management for events

- External communication on specific projects or topics

Tonkin (2005) provides a table that lists different features of various wiki software available in the market to help readers compare them and select the one that best meets their organisation's needs. Fichter and Wisniewski (2008) recommend the following best practices for implementing an intranet wiki:

1. Find a champion

2. Choose the right wiki software

3. Build initial structure and content

4. Train staff and relinquish control

5. Appoint a wiki gardener

\subsection{E-government}

'Digital government' or 'e-government' services are about 'the application of information technology, combined with changes in agency practices, to develop more 
responsive, efficient, and accountable government operations". (National Research Council, 2002, p.3).

Why should governments want to become more "responsive"? Perhaps it's because the relationship between the citizen and the state is being redefined. To quote from a special report on technology and government (The Economist, 2008, p.19.):

Citizens are not only the state's customers; they are also its owners. The term often used in the jargon of government technology is citoyen, reflecting the French idea of the politically engaged citizen.

Indeed, reporting on a workshop held to discuss the social and economic factors shaping the future of the Internet, the Organisation for Economic Co-operation and Development had noted (OECD, 2007, p.27.):

There was a general acceptance of the multi-stakeholder model, as a legacy of the World Summit on the Information Society (WSIS) and widespread recognition that governments are no longer the only problem-solvers but need to co-operate with other stakeholders.

Two years prior to the above-mentioned workshop, the OECD was cognisant of the fact that developing user-focused services would have structural implications for government, and had recommended that services be organised around users rather than around government agencies. (OECD, 2005). 
There is evidence of attempts by governments to work with their stakeholders using the Internet as a medium. In the United States of America, Garson (2006) gives the example of how, in 1997, the Department of Agriculture became the first federal agency to use e-rulemaking after inviting Web-based comments on rules for organic foods. This initiative led to the development of the US government's Web portal, Regulations.gov in 2003 (see http://www.regulations.gov/search/index.jsp), where the public can find, view, and comment on proposed US federal regulations. Eggers (2005) provides the example of the 'e-Government Project' — an initiative led by American Senators Joseph Lieberman and Fred Thompson in 2000 that invited citizens to help draft future e-government legislation by commenting on ideas that they had put up on the website (an archived version of the website is available at http://hsgac.senate.gov/egov archive/). Noveck (2008) discusses how, in June 2007, the US Patent and Trademark Office launched 'Peer-to-Patent: Community Patent Review' (http://www.peertopatent.org/), a project that uses the Web to seek contributions from members of the public that help patent examiners decide whether an invention is novel enough to be awarded a patent.

In the United Kingdom, Mulgan, Steinberg and Salem (2005) have advocated the use of open systems to facilitate collaboration between citizens and the state as a means of improving the legislative process. Hilary Armstrong, then Minister for the Cabinet Office, commissioned an independent review called 'The Power of Information' by Ed Mayo and Tom Steinberg in February 2007, to explore the role of government in working with user-generated communities that share information with citizens. Mayo and Steinberg recommended, among other steps (2007, p.43): 
To maximise the potential value of civil servants' input into online fora, by autumn 2007 the Cabinet Office Propriety and Ethics and Government Communications teams should together clarify how civil servants should respond to citizens seeking government advice and guidance online.

In its response, the Government accepted the above recommendation and thirteen others in their entirety, while partially accepting the remaining single recommendation (Cabinet Office, 2007). These recommendations were made to ensure that the government did not duplicate work already done by online communities, and that the government made public information available to the public — free of charge. Consequently, a Power of Information Taskforce was set up, and it has organised a competition that invites citizens to submit ideas for better ways to present public information, and new ways to put this information to use (see http://www.showusabetterway.com/). And in June 2008, the Cabinet Office published its guidance for civil servants who wish to participate in online fora, basing its advice around the following 5 principles (Cabinet Office, 2008):

- Be credible

- Be consistent

- Be responsive

- Be integrated

- Be a civil servant

The OECD draws a distinction between governments posting information online simply to inform citizens — an act that it regards as being part of e-government 
policies), and governments using Internet-based tools to stimulate comments or discussions among citizens - which the OECD acknowledges is a rapidly developing area, and one that authorities are turning to in an effort to increase their efficiency and be more pro-active in their relationships with their constituents (OECD, 2007).

Chen (2007, p.47) advises public sector managers to consider the following questions while choosing a channel to engage with their stakeholders:

- What are the available technical options?

- What are their characteristics?

- How do these match the audience needs?

- How do these reflect the objectives of the project?

- To what extent do they afford the degree and type of interactivity required?

A reality check, however, is offered by Hernon and Cullen (2006, p.361), who observe:

It is unlikely that governments intend to extend the political process beyond current levels of citizen input to decision making through well-established procedures, whether or not these are online. ... E-government may increase the number of channels used to facilitate these activities, but it does not necessarily in itself enhance citizen participation in government decisionmaking. 


\subsection{Government wikis}

Keeping in mind the comments made by Hernon and Clarke, it is worth looking at the use that some government organisations overseas have been making of wikis.

- Intellipedia (https://www.intelink.gov/wiki), a wiki available to the 16 agencies that make up the American intelligence community. Access is restricted to authorised personnel from these agencies.

- Diplopedia (http://www.state.gov/m/irm/ediplomacy/115847.htm), an internal wiki available to authorised personnel in the U.S. Department of State.

- GCpedia (http://tbs.clients.fenix-solutions.com/index.php/Main_Page or http://www.gcpedia.gc.ca/), an internal wiki for use by employees of the federal government of Canada. Currently at proof-of-concept stage.

- Future Melbourne (http://www.futuremelbourne.com.au/wiki/view/FMPlan), a wiki to help create a vision for the city of Melbourne, replacing the current City Plan 2010. Open to all, though registration under one's real name is required.

It doesn't look like a lot of activity has been reported in the area of wikis being used by government agencies. Guy (2006) had reached a similar conclusion while examining the use of wikis by public sector agencies on both sides of the Atlantic. Delving deeper, Guy had identified certain barriers to the use of wikis:

- Technical barriers: 
- Deciding on which software to use, keeping in mind that it may be necessary to migrate to a different system in the future

○ Non-technical drivers of the project will have to depend on people in the systems team to implement the wiki, and make changes as and when required. There is also the element of technophobia on the part of some when confronted by a new tool.

- Cultural barriers:

○ Leaders in an organisation may feel threatened by freedom to publish that wikis give staff, and some aspects of wiki usage may fly in the face of an organisation's policy of acceptable use

- Legal liability to the organisation in case of breaches of copyright and/ or intellectual property by staff who have posted content on the wiki

- Availability of sufficient resources to introduce a wiki, train staff on using it, manage, monitor and moderate it

○ Coping with possible vandalism by users

$\circ$ Encouraging uptake among users

- Other barriers:

$\circ$ Preservation issues (the problem of archiving frequently changing content)

- Lack of metadata for pages

○ Problems with standardisation of mark-up

○ Concerns about the quality of information available on the wiki 
Taking all of the above into account, it is remarkable to find examples of government agencies that have taken the initiative to use wikis as a means of collaborating with their stakeholders. This study will take a closer look at three such wikis in New Zealand. 


\section{Chapter 4: Research Design}

In this chapter, I explain my reason for electing to perform qualitative research, and why I have decided to conduct a phenomenological study. I then provide an account of my research sample, describe my method of collecting and analysing data, and end with a statement on the limitations of this study.

\subsection{Research method}

My study was intended to draw lessons from the experience of New Zealand government officials who have used Web 2.0 tools to collaborate with their stakeholders. The lessons that I sought would come from the insights of these officials when they had the opportunity to reflect on their experience. It seemed to me therefore that a qualitative approach — rather than a quantitative approach — would suit my research, as the following definition of qualitative research helps explain (Gorman and Clayton, p.23):

Qualitative research is a process of enquiry that draws data from the context in which events occur, in an attempt to describe these occurrences, as a means of determining the process in which events are embedded and the perspectives of those participating in the events, using induction to derive possible explanations based on observed phenomena.

According to Leedy and Ormrod (2001, p.148), qualitative research studies help the researcher to: 
(a) gain insights about the nature of a particular phenomenon,

(b) develop new concepts or theoretical perspectives about the phenomenon, and/or

(c) discover the problems that exist within the phenomenon.

These characteristics of qualitative research match my research objectives. What I expect to gain from this study is an understanding of how certain New Zealand government organisations have deployed Web 2.0 tools to collaborate with their stakeholders, how they have benefitted from this experience, how they overcame the barriers that they faced, and how they encouraged their stakeholders to make use of the tools that they deployed. Through this study, I hope to share the lessons that these government officials have learnt from their experience with those officials in other government organisations who might be contemplating using Web 2.0 tools to collaborate with their stakeholders, and who would like to find out what the experience has been like for the trend-setters.

I had read about the five common qualitative research designs described by Leedy and Ormrod (i.e., Case Study, Ethnography, Phenomenological Study, Grounded Theory Study, and Content Analysis), and I had also read about the Mixed Methods Procedures research design described by Cresswell (2003).

Leedy and Ormrod provided the following definition of a phenomenological study (p.153): 
A phenomenological study is a study that attempts to understand people's perceptions, perspectives, and understandings of a particular situation. In other words, a phenomenological study tries to answer the question, What is it like to experience such-and-such?

I considered phenomenological study to best meet the requirements of my research because I felt that I could use the following features of a phenomenological study to obtain a rich and deep understanding of the experience of New Zealand government officials who have taken the first steps in using Web 2.0 tools to collaborate with their stakeholders:

(a) lengthy interviews with participants usually varying between 1 and 2 hours, which allows for the subject to be discussed in detail;

(b) a carefully selected sample of participants, with a typical sample size of between 5 and 25 participants (i.e., the key people involved in the event);

(c) an unstructured interview format that allows the respondent to touch upon any issue that $\mathrm{s} / \mathrm{he}$ considers to be germane to the subject

I wanted to complete this study with the feeling that having obtained multiple accounts from New Zealand government officials who were instrumental in rolling out Web 2.0 applications that they used to collaborate with their stakeholders, I might be in a position to draw a general picture of the conditions under which a government organisation could decide to make use of a Web 2.0 tool, how it could make the best possible use of the tool, and how it could overcome the pitfalls it might face on the way. 


\subsection{Research sample}

I started the process of selection of participants by searching for wikis in New Zealand's public sector that government organisations were using to collaborate with their stakeholders, and found four wikis that were accessible by members of the public. The reason for searching for wikis was that they epitomise a Web 2.0 tool that is collaborative by design. I then initiated contact with the officials responsible for administering these wikis, and had preliminary talks to ascertain: (a) if they were agreeable to their wikis being the subject of an MLIS research paper, and (b) who were the other key officials responsible for developing and administering the wikis. I was looking for officials who had a key role in administering or in implementing the wikis, or in developing the policy guiding the use of the wikis. In that sense, the selection of participants was both purposive and stratified (Gorman and Clayton, 1997).

Of the four wikis, one had to be dropped from the purview of this study at the outset after the officials responsible for administering it declined to be part of the study. Of the remaining three wikis, two were hosted by an organisation that had already had some experience in implementing wikis, while one was hosted by an organisation that had developed a wiki for the first time. Officials from both these organisations expressed their willingness in being part of the study, and I therefore wrote to authorities in these organisations to formally seek permission to interview staff in the organisation's premises for the purpose of the study. Permission to interview staff in the premises of the organisation was readily granted by the authorities. 
I then made a list of nine officials I wished to interview, and contacted them to make appointments. Simultaneously, I sent each of them a formal invitation to participate in the study, and this letter was accompanied by a list of questions that I would ask them, as well as a Consent Form that they would need to sign and return to me should they agree to be interviewed. All the nine officials I contacted were keen to participate in this study; in fact, one of them even brought along a colleague to the interview so that the colleague - who had had significant involvement in the development of two of the wikis - could provide additional information. Participants were given the option to withdraw from the study without giving a reason anytime before 24 January 2008, and with the assurance that any data that they had provided would be destroyed upon intimation of their intention to withdraw. None of the participants expressed a desire to withdraw from the study.

\subsection{Data collection}

I conducted the interviews face-to-face and one-on-one (with the exception of the interview where the respondent had brought a colleague along) in the offices of the participants. The interviews were semi-structured because I had provided participants with a list of questions in advance. However, each participant was asked at the end of the interview whether s/he had anything else to add. The questions were open-ended, and the atmosphere was cordial, which encouraged participants to relax and express their thoughts without feeling constrained.

I recorded the interviews using a digital voice recorder, having first obtained the permission of the participants to record the interviews, in adherence to human ethics procedures. I transcribed the interviews myself in order to ensure confidentiality. I 
had mentioned in my invitation to participants that I would anonymise their identity, though the identity of the organisations themselves might be revealed. I had also offered to send participants a recording of the interview as well the transcript, so that they could verify the latter and amend it if required.

Upon transcribing the interviews, I sent the transcript along with the recording to each of the participants, so that they could verify the transcripts. This approach enabled me to request the respondents to clarify what they had said on the odd occasion where I hadn't been able to transcribe a part of their response due to a difficulty in understanding what had been recorded. Only one participant had requested me to delete certain sections of the transcript. I started the process of data analysis after receiving the verified transcripts back from the participants.

\subsection{Data analysis}

For the purpose of data analysis, I followed the process described by Leedy and Ormrod (2001). I selected statements from the transcript that were pertinent to my research questions, and discarded the rest. I refined my selection by breaking it down to the level of sentences/ phrases each of which represented a single thought. I then assimilated these smaller parts into more cohesive groups that represented different facets to a particular question, based on varying perspectives of the different respondents. These multi-faceted groupings which contained both similarities of opinion as well as divergent views helped me create a comprehensive picture of the near-totality of the experience that I was exploring. 


\subsection{Limitations of the study}

This study is exploratory by nature, and limited to the views of nine participants from two central government organisations in New Zealand. It could be improved upon by widening its scope to include more subjects from other government organisations in New Zealand. I had selected just these two organisations as they were the only organisations that had used a wiki to collaborate with their stakeholders at the time when I was conducting my study — and because they were willing to participate in my research.

I had also decided to restrict the scope of the study to one kind of a Web 2.0 tool the wiki - because it is particularly well suited to collaborative work. There are other Web 2.0 tools that could be considered for a similar study, e.g., blogs, mash-ups, social bookmarking, social cataloguing, social search.

At a later date, if there are more government organisations in New Zealand that start using Web 2.0 tools to engage with their stakeholders, it might be time to conduct a wider study. Future studies may also look at expanding coverage in terms of other Web 2.0 tools, and perhaps focusing on the perspective of users. 


\section{Chapter 5: Setting up the Wiki}

This chapter investigates the reasons that participants have provided for selecting the wiki as a tool to collaborate with their stakeholders. It also looks at the how the decision to set up a wiki was taken in the participant's organisation, and the role played by the participation in decision-making.

\subsection{Reasons for selecting a wiki}

The most common reason, advanced by three of the respondents (R2, R4 and R9) for setting up a wiki in preference to a different application for sharing information (such as a shared workspace) was that it enabled collaborative creation of content. In fact, R9 went on to say that Microsoft Office SharePoint wasn't able to provide the kind of customisation that was required, whereas MediaWiki was able to do so. On a related note, R10 had mentioned that using a wiki enabled information to be shared and kept current.

Two respondents (R2 and R4) favoured a wiki because the tool matched the requirements of the project. In R2's opinion, a wiki enabled stakeholders to work together in creating a knowledge-base, while R4 mentioned that the choice of a wiki enabled the team to "practice what we were preaching" with regard to Wiki 2.

While the novelty of the tool was mentioned by two of the respondents (R6 and R8) as a reason for opting to use a wiki, two other respondents (R4 and R10) explained that it was the familiarity of the tool among a critical mass of users who had prior 
experience of using it — and, consequentially, realising its advantages — that helped them decide to use it. R8 felt that the novelty of using a wiki as a supplement to the standard process of consultation with stakeholders helped boost the response.

Yet another factor favouring the choice of a wiki was that it was, technically speaking, easy to set up (R8) and non-intimidating for users (R1). R7 noted that a wiki was easy to access, both by an internal audience as well as by an external audience. R6 extended this idea by stating that a wiki was deliberately selected in order to be able to reach "hard-to-hear" stakeholders, who might otherwise have been left out of the consultation process.

R5 had a couple of interesting reasons to offer for the choice of a wiki: a desire within the organisation to experiment with new technology on the one hand, and as a way of determining where the gaps lay in the way in which the organisation managed information, on the other (as well as attempting to see if the use of a wiki could plug those gaps).

\subsection{Participants' role in decision-making}

Responses to the question on how the decision to create a wiki was taken — and the role played by respondents — were varied.

One group of respondents (R1, R2 and R3) belonged to the same team, and said that the decision to create a wiki was taken before they had joined the team. R2's role was to implement the project, having been brought in to cover the role of the Project Manager, who was away at the time. 
R4, a Project Manager, decided to use a wiki on the basis of prior experience of using one, and also because it would provide project participants with the opportunity to become familiar with the tool.

R6 and R7 said that the idea of using a wiki originated in a groupthink brainstorming session on inexpensive and interesting ways of getting stakeholders involved in the project. R8 had prior experience of using a wiki and proposed the idea of using one, while R6 supported it.

R5 said that there hadn't been a formal decision-making process as such, and didn't think that senior management had been involved in taking a decision to use wiki technology. The software was available in a stand-alone computer, and staff with an interest in wikis were experimenting with it to learn how it worked.

In terms of the role played by participants in the decision-making process, three respondents (R2, R4 and R7) were Project Managers, and it would be fair to say that their support was key for the adoption of wiki technology in their projects.

Two respondents (R8 and R9) were instrumental in providing their teams with wikis to trial before going ahead with the project. $\mathrm{R} 8$ had prior experience of using a wiki, and occupied an advisory role in the team - having proposed the idea, to begin with.

R10 wasn't quite as much involved in the process of decision-making that led to using a wiki; however, once the decision was taken, R10 played an important role in 
identifying users and systems for security and helped the business owners understand the consequences of implementing different models.

\subsection{Discussion}

While the responses of participants don't reveal an inclination towards a particular set of reasons, these interviews have been able to bring together a host of reasons that made respondents decide to opt for a wiki instead of a different application. One area that emerges from their responses is that covered by the inherent features of a wiki:

- it is a tool that is comparatively easy to use;

- it is a Web-based tool, hence accessible to anyone with an Internet connection;

- it has been designed for collaborative creation of content, and can even function as a knowledgebase;

- it is easy to set up, and can be customised

Among these features of the wikis lie some of the advantages mentioned by Klobas (2006). Other reasons advanced by respondents relate to the requirements or conditions of their project. Nevertheless, the fact that government organisations have started to use a tool that enables them to create content in collaboration with their stakeholders is, in itself, quite encouraging.

Participants' responses have also provided insights into the different roles played by various team members in the adoption of wikis in their projects, as well as the circumstances under which some of these decisions were taken. 
One response that stands out is that the idea of using a wiki emerged from a brainstorming session (R6 and R7) — as a relatively inexpensive and interesting of getting stakeholders involved in the project. This response highlights two other features of the tool: that it is relatively inexpensive (hence can potentially be deployed by other government organisations without worrying too much about budgetary constraints), and that its use by a government organisation is considered to be novel.

It is perhaps unsurprising that the decision to opt for a wiki as the tool of choice was taken following the recommendation by a team member who had prior experience of using a wiki; certainly, the case for a wiki would have been strengthened when the team member set up a test wiki for other members to trial, given the tool's match with the project requirements. 


\section{Chapter 6: Wiki - Benefits and Strategies}

This chapter looks at the benefits that participants consider their organisation to have accrued from using a wiki to collaborate with stakeholders. It also explores the strategies that participants mention their organisation having used in order to reap the benefits of using a wiki.

\subsection{Benefits of using a wiki}

The question on benefits that have accrued to the organisation following the use of a wiki to collaborate with its stakeholders yielded a number of responses, many of which lent themselves to certain common themes.

\subsubsection{Transparency}

Transparency stood out as one theme. While R1 said that the wiki gave its sponsors "an image of being honest and open" about the project, R4 noted that the wiki made the process of policy development "incredibly transparent". R9 felt that increased transparency created almost an "obligation to action", which resulted in preventing issues from slipping through the cracks. $\mathrm{R} 2$ had expectations that the wiki would enable a "transparent, open and productive consultation process" leading to a "cycle of continuous consultation".

\subsubsection{A conduit for information to flow}

Another advantage, following on from the point made by $\mathrm{R} 2$ above, is the ability of the wiki to act as a conduit for information to flow in multiple directions simultaneously. R1 and R2 mentioned that the wiki could act as a mechanism to 
collect information from individual users and make it available to the community of users/ members of the project; in time, the wiki could serve as a knowledge base or repository. R2 found the wiki to be a tool that could enable those users who had spotted a problem to also suggest a solution. Being a Web-based tool, R4 felt that the wiki enabled users to contribute to the project — regardless of their geographical location. R9 considered the wiki to be a new channel that allows information to flow, supplementing existing channels.

\subsubsection{Enhancing engagement with users}

The above-mentioned advantages of a wiki lead us to the next theme, i.e., the wiki as a tool that enhances engagement with users. While R5 described the wiki as an excellent tool for engaging with users, R1 and R3 felt that the wiki increased involvement — and ownership — among the community of users. There is also the spin-off benefit of the wiki increasing engagement among users. According to R4, the wiki enabled creation of a 'many-to-many' relationship among users, while R5 used the expression "a catalyst for collaboration" to describe it. R10 said that a wiki allows a discussion to start where one wouldn't have taken place earlier, while R6 and R7 acknowledged that the wiki was responsible for an influx of new ideas from users. R4 felt that a wiki provided a forum for users to discuss how to deal with emerging issues of common concern.

\subsubsection{A communications tool}

The final theme is with regard to the wiki as a communications tool. $\mathrm{R} 8$ said that that the wiki helped reach people who had not been reached before. R6 and R7 were struck by the publicity that their use of the wiki brought to their project; in R7's 
words, the wiki "exceeded expectations as a communication exercise in awarenessraising". R6 felt that the wiki enhanced the prestige of the organisation and the country as forward-thinking and willing to take challenges; R8 said that their use of the wiki "gained kudos within the online community".

An interesting advantage highlighted by R5 was that the use of a wiki yielded a better understanding of the wiki technology — especially the risks and the pitfalls. This aspect will, however, be examined in detail in a subsequent chapter.

\subsection{Strategies for using a wiki}

The project teams responsible for running these wikis have — in keeping with the purpose of the wiki and its audience - employed very different strategies in order to reap the benefits of using the wikis as a tool for engaging with their stakeholders.

Wiki 1 was launched without a strategy per se for engaging with stakeholders which is not surprising considering that it was targeted at a niche audience, and that the wiki itself was born out of a process of consultation with its stakeholders. Further, its users were knowledgeable about the use of a wiki, and didn't need to be persuaded to try it. Awareness of the existence of the wiki was raised through articles in local and trade publications; key stakeholders were informed about the launch of the wiki, and it was publicised through standard listservs.

Free training courses on accessibility, usability and the use of the wiki were offered to users of the Wiki 1. This idea was further developed in the case of the Wiki 2, where individual users were telephoned by members of the project team to enquire how they 
were getting on, and if they would like to avail themselves of a free, one-on-one training session on using the wiki. A communications strategy had also been developed for Wiki 2, identifying stakeholders and describing how they would be introduced to the wiki; this strategy was supported by a lot of offline activity, such as lunchtime meetings, workshops, email correspondence, etc.

Another strategy that had been consciously developed in the case of Wiki 2 was to recognise that the wiki was just one of various channels to engage with stakeholders, and no attempt was made to impose it upon project participants, since some participants were expected to be uncomfortable with using a new technology. However, the wiki was positioned to be a central repository of all relevant information about the project; it thus drew users to it - particularly when they found that it was mimicking the policy development process that they were familiar with, as information in the wiki was captured into a record management system at intervals.

Wiki 3 was one that had employed a very simple strategy: a group of stakeholders had been identified and was informed about the launch of the wiki by email; simultaneously, a press release was used to inform the public at large about the existence of the wiki. The ensuing popularity of Wiki 3 in the media and its use by members of the public exceeded all expectations of the project team, which had deliberately refrained from targeting traditional stakeholders in order to obtain the views of the general public; indeed, the team found itself stretched in order to keep up with the response. The wiki included a page for participants on behaving properly, emphasising the good qualities that were expected of them. Further, it was stated on 
the wiki itself that the pages would be moderated, and moderation was carried out to ensure that the wiki was kept free of vandalism.

\subsection{Discussion}

To summarise, the advantages of a wiki revolve around its use as an information conduit-cum-knowledge repository, as a tool that enhances engagement with and among users, and its use as a novel and transparent communications tool.

Responses from participants have brought to the fore advantages of a wiki that extend beyond those stated by Klobas (2006). Indeed, the above-mentioned advantages are more closely allied to the 4Cs approach to classifying social software, as advocated by Cook (2008), on the basis of the primary functions of the tools, i.e., communication, co-operation, collaboration, and connection.

The theme of transparency as an advantage is possibly one that fits well with the ethos of the public sector in New Zealand. Of interest is R9's remark that the increased transparency brought about by wikis can help prevent issues from slipping through the cracks. While laying policy issues out in the open for others to see (and comment on) might be a revolutionary step for the public sector to take, it can only help in ensuring that promised action is not forgotten.

Commenting on the advantages of the wiki as a tool that enhances engagement with users, R10 provided a fresh insight in saying that a wiki allowed a discussion to start where one wouldn't have taken place earlier. A wiki not only enables connections to be made among users, but also allows new ideas to be born through the 
interconnection of existing ideas. By being a central repository for existing information, a wiki also acts as a magnet that attracts new ideas from users, as R6 and R7 have mentioned.

A couple of comments about the advantages of the wiki as a communications tool are worth highlighting: R9's comment about wikis being a supplementary channel and R8's comment about wikis being able to reach niche audiences. To the majority of today's users, it is important to stress that wikis serve to supplement traditional channels of interacting with an organisation's stakeholders. However, with growing numbers of people working online — and this brings to mind the so-called 'digital immigrants' and the 'digital natives' — it is only a matter of time before an organisation's stakeholders would expect to be consulted using digital media. What starts out as a trend today may well become tomorrow's norm. In that respect, it is just as well that government organisations have started to use Web 2.0 tools such as wikis, as the experience will make them familiar with tools that they may have to use increasingly in the future.

The strategies used by the organisations that deployed the three wikis seem to have focused on marketing the wikis to their stakeholders through traditional steps: identification of the target group, advertisement, product launches, the provision of training, etc.

Interestingly, in the case of Wiki 3, a strategy that was adopted — and which paid unexpectedly large dividends — was viral marketing. Manchester (2007) alludes to this strategy in the checklist of top 10 issues that an organisation should consider 
while developing its social media strategy, advising organisations to take a hands-off approach to marketing the tools. The idea for Wiki 3 was so novel that those who came to know about it through the initial press release spread the word to others and word spread like wildfire in cyberspace. The organisation did not have to do anything else to promote Wiki 3; on the contrary, the organisation had to allocate resources to deal with the sheer number of users who were trying to access the wiki. In addition to members of the target group, those trying to access Wiki 3 included vandals, as well; however, the idea of this wiki captured the imagination of many.

Wiki 2 adopted a mature approach in engaging with its stakeholders — it was positioned in such a way that even reluctant users would, over time, take to it. The strategy was subtle: don't force it on the users, stress that it would supplement existing channels, make it a repository for all relevant information, and include processes that users were already familiar with.

While the strategy to be adopted would depend on the nature of the wiki and its target audience, it is clear that the objective is to get members of the intended audience using the wiki. The strategy may need to be adjusted, depending upon the outcome of initial efforts, so long as the message about how the wiki would benefit its users is carried through. 


\section{Chapter 7: Overcoming Technological Constraints}

This chapter deals with an important part of the experience that participants have had of using a wiki - encountering technological constraints. It then looks at the measures that they took to overcome those constraints.

\subsection{Technological constraints}

The responses of interviewees to the question on technological constraints that they faced in implementing the wiki indicate that there weren't too many such constraints.

A recurring theme in participants' responses appears to be the selection of a tool or software to build the wiki that would be compatible with the business environment of the organisation. For instance, in R2's opinion, a technological constraint was that software used to build the Wiki 1 would have to be compliant with the principles they were advocating; hence the decision to select MediaWiki, despite security concerns around the openness of this software application.

Then again, R6 felt that a technological constraint was that Wiki 3 would have to be one that could be viewed on internal computers used by staff notwithstanding the restrictions placed on such computers by the organisation, e.g., the inability to download cookies, or view a lot of Java script. According to R7, another restriction on the software to build this wiki was that the wiki would have to meet State Services Commission (SSC) requirements for wiki technology. Interestingly, R1 had considered the prospect of having to use the mandatory Government Logon Service 
(GLS) for New Zealand government websites as a technological constraint, as it went "against the Web 2.0 philosophy".

Security of the software used to build the wiki was put forth as a technological constraint by R3 and R8 of the Wiki 1 and Wiki 3 respectively. It was felt that the wikis could attract the attention of vandals, particularly because they had been published by government organisations. R8's team finally decided to use PMWiki instead of MediaWiki, as they encountered security issues with MediaWiki that made them uncomfortable with the idea of using it. Wiki 1 was unlikely to attract the attention of vandals given its subject matter, and it was safely deployed despite using MediaWiki. However, Wiki 3 encountered a fair amount of vandalism — possibly because of its subject matter - during the period that it was live, and, in hindsight, it seems to have been a wise decision on the part of the team to eschew MediaWiki in favour of PMWiki.

A further technological constraint identified by $\mathrm{R} 9$ was the lack of a cost-effective and lightweight hosting solution for the wiki, as the SSC's hosting arrangements were constructed on the basis of larger, heavyweight applications which require "high uptime" and are expensive to host.

Finally, a significant constraint, in the view of R3 and R4, was the lack of technical support. This constraint was not, strictly speaking, technological, but was centred around the lack of people working on the project with adequate technical knowledge to develop the wiki. Indeed, R3 reported feeling "exposed" due to the lack of PHP programming knowledge required to use MediaWiki. R4 acknowledged the 
availability of "in-house expertise" in the ICT branch of the organisation, but also said that they were relying very much on "people actually using their own resources" due to the limited resources within the branch. R9 also considered a lack of technical knowledge in wiki administrators to be a constraint, and felt that business-oriented roles, such as theirs, required a degree of technological skill in order to administer the wikis, as life would become a bit harder if technical people had to be called upon in order to make every little change to the wiki. R7 went a step further by stating that not having staff at the senior administrator level for the wiki who have the technical expertise required to block attacks by vandals would have been a constraint.

On the other hand, R5 didn't think there were any technological constraints as "the tools are incredibly simple to implement", and R9 had also said that they "were lucky in having some people in the organisation, some technical support people who were familiar with the sort of Linux-Apache-MySQL-PHP environment that we run MediaWiki into." Even R4 noted that "the advantages with some of these Web 2.0 tools - they are very easy for a non-technical person to take up."

\subsection{Dealing with technological constraints}

The manner in which the teams responsible for deploying the wikis overcame the technological constraints that they faced suggests that there was little in common in their approach — which is understandable when one considers that they were responding to challenges that were unique to their situation.

With regard to the security of the wiki, R7 and R8 said that they tested different wiki products before deciding to use the one that met State Services Commission 
guidelines and was most suitable for the purpose. R3 stated that they had tested the security of the system by attempting to hack into Wiki 1 and hijack sessions, and R2 mentioned that they had developed an extension to MediaWiki to improve authentication and security that enabled automatic lock-out after 5 failed attempts to login to the wiki.

R1 said that their team had bypassed the mandatory Government Logon Service (GLS) after receiving explicit approval from management to do so. R2 clarified this statement by saying that they had explained their reasons to the Authentication Group in SSC for not using the GLS — the fact that Wiki 1 was a pilot project, that it had a low risk profile, and that it was operating on a low budget appears to have persuaded the SSC's Authentication Group that their wiki could be deployed without having to use the GLS.

R9 said that they hired virtual hosting that met the SSC's minimum security requirements in an attempt to deal with the challenge of finding a cost-effective solution to hosting what was essentially a free software that didn't warrant "high uptime”. R8 reported making similar arrangements to deploy Wiki 3 on a rented virtual server, thus isolating it from the network of the organisation's internal computers.

To overcome the constraint of technical support, R3 said that they had borrowed the services of a developer from another government organisation for 2 weeks to develop Wiki 1; they had also issued a Request For Proposal (RFP) for supplying technical skills on an 'as-needed' basis. 
This approach in dealing with the constraint of an inadequate base of technical support found an echo in the response of R4, who said that had contracted technical support on an 'as-needed' basis. R4 also said that they had relied on the expertise and advice of one of the Business Analysts in the team, and that they developed the required skills within the project team, and depended on people using their own resources.

\subsection{Discussion}

Two of the points noted by Guy (2006) as technical barriers to wiki use find an echo in the responses from participants — wiki software selection, and dependence on technically-savvy staff to drive the tool. While Guy had referred to software selection from the perspective of future-proofing the system, the issue highlighted by respondents here is one of compatibility with existing systems in the business environment. The matter of selecting a wiki software programme would also involve the familiarity of technical staff within the organisation with the programming language used for the software; as R9 had said, they were lucky to have people who were familiar with "the sort of Linux-Apache-MySQL-PHP environment that we run MediaWiki into".

There appear to be conflicting views on the second point, i.e., dependence on systems people to drive the tool. While R5 felt that the tools were "incredibly simple to implement”, R3 — despite having a technical background — reported feeling "exposed" due to the lack of PHP programming knowledge required to use MediaWiki. Differing perceptions could be at play here. R5's comments may have 
been made from the perspective of an ordinary user, and perhaps installing wiki software and using it may well be relatively straightforward. However, from a developer's perspective, it does appear that knowledge of the programming language used by the software is essential if one is required to customise/ modify the software to suit the organisation's requirements.

Comments made by R6 about conforming to an organisation's IT usage policy, and those made by R7 about complying with SSC requirements for wiki technology will probably be reported by future users from government organisations in New Zealand as one of the initial constraints that they will face. Fortunately, there are dozens of wiki software packages to choose from, and the Wikimatrix website (http://www.wikimatrix.org/) can help potential users select the wiki software that will best meet their requirements. Would-be users from the government sector will, no doubt, rank the security features of the software near the top of their list of essential features while considering the options.

What emerges from the measures taken by respondents to overcome the technological constraints that they had faced is a number of precedents for others from the government sector to follow, should they wish to do so.

For instance, the extension to MediaWiki that locks a user out after 5 failed attempts to logon that R2 has referred to is a part of open source software that anyone can use. It may well be one of the reasons that makes the SSC waive its GLS requirement should another government organisation find itself in a situation similar to the one faced by Wiki 1. Following on in the footsteps of Wiki 1 and Wiki 2, other 
government organisations may wish to hire the services of a virtual server that meets the SSC's minimum security requirements, if they would like to host their wiki offsite; indeed, it appears that Wiki 3 may have followed in the footsteps of Wiki 1 and Wiki 2, in this regard. 


\section{Chapter 8: Pitfalls and Risks in Wiki Usage}

This chapter considers the pitfalls that — in the opinion of respondents - New Zealand's central government organisations face in using Web 2.0 applications such as wikis, in collaborating with their stakeholders. It then reports on the measures that respondents have taken to manage the risks from users of their wikis.

\subsection{Potential pitfalls}

On the basis of their experience in launching and administering wikis, respondents provided a significant amount of feedback in answers to the question on pitfalls that an organisation could face in using Web 2.0 tools such as wikis to collaborate with their stakeholders. Their concerns can be grouped under 5 themes:

\subsubsection{Suitability of the tool for the purpose}

R5 pointed out that a very clear strategy with regard to the desired outcome is a prerequisite, and that the selection of the tool should be the last step - it should be considered in the context of the business objective, the state of the current work environment in terms of a collaborative culture, and what tools would be required to bring about a culture of active collaboration. R6 also underscored the importance of making sure that the tool being used was appropriate for the audience and purpose.

R1 and R2 felt that a pitfall could be the danger of jumping on the Web 2.0 bandwagon, and consequently, using a tool that might not be suitable for the purpose. R1 also cautioned against using a wiki/ blog for no real purpose, or for a purpose that 
doesn't really fit in with the policy programme/ communication plans of the organisation.

In taking a 'big-picture' view, R4 warned against the danger of becoming too wrapped in technology and looking for technology-driven solutions, as opposed to business-driven solutions.

\subsubsection{Resource-intensive nature of Web 2.0 applications}

R2 cautioned against underestimating the effort required to maintain Web 2.0 products, saying that a huge amount of effort was involved in monitoring, moderating, writing, and managing communities online. $\mathrm{R} 2$ then pointed out that a balance needed to be maintained between the user community's need for responsiveness vis-à-vis the resources available to the organisation.

R9 felt that a challenge could present itself with Web 2.0 applications enabling users to comment instantly — it resulted in there being "almost an obligation" on the part of the wiki administrators/ moderators to "respond immediately".

R2's view on the resource-intensiveness of Web 2.0 applications was echoed by R8, who said that when an organisation sets up a wiki, it pre-supposes that the organisation is willing and able and wanting to engage with its community of users, and "it pre-supposes the existence of staff in-house, who are willing and able with time and resource and the wherewithal to respond to stuff that's happening". 


\subsubsection{Dealing with vandalism and legal liability}

While R3 felt that dealing with badly-behaved users online would present a challenge to the organisation, R9 insisted on conservatively applying "business rules for registration and editing" out of a concern about the possibility of vandalism.

$\mathrm{R} 2$ presented an interesting dilemma for government organisations wanting to deploy Web 2.0 tools to engage with their stakeholders: on the one hand, the success of a Web 2.0 tool is dependent on establishing and maintaining trust within the community of users (inclusive of moderators and administrators); on the other hand, government organisations aren't expected to fail, and being a part of government means that such organisations can expect to be targeted by vandals. How then, does one balance the risk of vandalism with the need for trust within the community of users?

$\mathrm{R} 1$ brought up the issue of legal liability of the government organisation that hosts a wiki — is it legally liable for offensive/ illegal material that has been posted by a member of the community of users? R1 had received advice that the organisation would not be legally liable under such circumstances if it were to make "an honest and extremely prompt attempt to get the stuff off again". However, this solution only reinforces the point made earlier about Web 2.0 tools being quite resource-intensive. Not to mention the need for moderators to be ever-vigilant.

\subsubsection{Engaging with users}

In R2's opinion, a possible pitfall could be overestimating the interest of people in communicating with the Government. R2 felt that it was important to recognise that 
members of the public may not be driven to contribute to a Web 2.0 tool simply because it has been made available to them by a government that wants to hear their views — and that this lack of participation by people could be a barrier to successfully deploying a Web 2.0 tool.

R6 felt that a lack of awareness among the general public about Web 2.0 tools precluded many from the opportunity of using them as means of engaging with government. R7 offered a different perspective, saying that wikis would appeal to a certain kind of person who is creative and is happy for his/ her creative input to be blended with the creative input of others.

R7 also touched upon the struggle to engage with users who are busy and may not have the time to contribute; alternatively, some people may simply wish to stick with familiar, formal channels of engaging with government, instead of using a wiki. R7 felt that managing the dilemma of providing a sufficient amount of free or interesting content to stakeholders, while not burdening them with too much information was another pitfall — evoking a possible scenario of user burnout if every government organisation started to run wikis with every stakeholder in New Zealand.

In R7's opinion, it is important to find a useful, formal outlet to the discussion on the wiki - otherwise, stakeholders would not find any value in the exercise. Not thinking about the deliverable arising from the process of engagement using a wiki — and communicating the same to stakeholders — is, in R7's opinion, a pitfall that may stall the success of future wikis. 


\subsubsection{Effect on users}

The final set of concerns about possible pitfalls focussed on the situation from the perspective of users of the wiki.

R7 thought that one of the pitfalls was the cost to organisations of staff having to learn a new skillset (i.e., the wiki markup language) in order to use a wiki at a time when most people are already under a lot of pressure with regard to their time and their work. R7 acknowledged that most wikis have WYSIWYG (What You See Is What You Get) editors, but even so, some people are "terrified by markup".

R7 also thought that not recognising the amount of time needed to make behavioural and cultural changes that are required to bring about effective change in organisations was a pitfall. R7 was concerned that people would not use new tools such as wikis and consequently the benefits of these tools would not be realised - if organisations did not plan carefully to provide resources, support and time for staff to manage the change successfully.

R4 warned against the danger of managing user expectations, particularly the danger of expectations among users that a new tool might overcome defects that are actually inherent in the process to which it is being applied. $\mathrm{R} 4$ felt it was important to clarify that the use of a new tool would not change anything if the process itself was fundamentally flawed.

Finally, R8 cautioned against the fear in New Zealand's central government agencies of Web 2.0 tools being used by the general public to interfere with their policies. R8 
noted the basic contradiction between the wiki practice of allowing users to modify and shape content, and the risk-averse nature of government organisations.

\subsection{Managing risks from users}

The three wikis that have been the subject of this research have used a variety of methods to counter the risks from users, vandals and hackers. These methods can be grouped under the following themes:

\subsubsection{Access to the wiki}

$\mathrm{R} 4$ noted that the process of granting membership to the wiki had been moderated to establish trust, and also to ensure that the community had a trusted environment in which members could interact. R4 said that for Wiki 2 they had developed a set of terms and conditions for membership to the wiki (in collaboration with the Legal team and Communications Manager of the organisation). R5 observed that membership to Wiki 2 was by invitation to a fairly well-defined group; hence, this approach was considered to be low-risk.

Members had to $\log$ on to access Wiki 1, and R1 said that this reduced the risk of the wiki being spammed. R9 observed that Wiki 1 had a system of locking out users who had failed 5 consecutive login attempts, as a means of guarding against hackers.

\subsubsection{Safeguarding content}

R10 mentioned that a rule applicable to members of Wiki 2 was that their user name had to be their real name, and that this rule would ensure that members were careful about what they posted on the wiki. R4 said that members of Wiki 2 were made aware that the content of the wiki could be made available under the Official Information 
Act, in an effort to forestall the posting of objectionable material. Another feature to safeguard content, mentioned by R9, was that only registered users could edit content on both Wiki 1 and Wiki 2 .

\subsubsection{Monitoring and moderation}

With regard to Wiki 1, R1 and R2 said that they had enlisted the assistance of members of a team of around eight Webmasters working in public sector organisations, who were given the responsibility of moderating sections of the wiki assigned to them and deleting inappropriate content. The degree of moderation was light, given its low-risk profile.

In contrast, Wiki 3 was subject to intense monitoring and moderation as a result of the worldwide attention it attracted from friendly and unfriendly netizens alike. R7 had said that, on advice from the State Services Commission, Wiki 3 had stated upfront that it would be monitored and moderated, in keeping with cyber ethics. While Wiki 3 was alive, R7 had four staff monitoring and moderating the wiki minute-by-minute; this was effective in curbing vandalism, as the vandals found that their posts were being removed immediately, while constructive suggestions were retained (which encouraged genuine contributors).

\subsubsection{Other measures}

R7 said that another measure that they had adopted for Wiki 3 was blocking the IP addresses of persistent vandals. At times, the wiki was put on hold for 5-10 minutes to encourage vandals to move on. The wiki was live only during business hours in New Zealand, which deterred — to some extent — vandals from overseas, as they were in a different time zone. 
R3 said that they had spent a week or so trying to hack into Wiki 1 to test its weaknesses, and then worked on fixing those weaknesses.

R4 brought an interesting perspective to the aspect of managing risks from users by saying that in the case of Wiki 2, they had used the terms and conditions for users to instil a sense of respect for the ownership of content on the wiki and its subsequent use by other members of the wiki.

\subsection{Discussion}

Some of the cultural barriers listed by Guy (2006) also come through in the answers from respondents, e.g., availability of resources, encouraging uptake among users, legal liability of the organisation, and dealing with vandalism. However, the participants' responses also highlight a number of other potential pitfalls, which are worth reiterating. Chief among these are failures to:

(i) appreciate the requirements of the business: Management literature can provide numerous examples of initiatives that failed to achieve their objectives because of a flawed strategy, or because a tool was selected that did not fit the purpose. For the project to succeed, it is essential to have a carefully-designed strategy before anything else, and one should not fall into the trap of looking for technology-driven solutions in lieu of business-oriented solutions - or jump on the Web 2.0 bandwagon.

(ii) appreciate the position of a government wiki: It is easy to fall into the trap of overestimating the interest of people in the wiki; it may actually be necessary to think 
of ways to attract the public to the wiki, given that the work of government is hardly regarded as enthralling. There is also the quandary of providing sufficient amount of free information that will attract the attention of the target group, but without causing information overload. It is also important to demonstrate the value of their contribution to stakeholders (if only to maintain an ongoing relationship), and this can be done by showing them how their contribution has affected the outcome of the exercise.

(iii) appreciate that change succeeds when it is cultural: An organisation needs to plan ahead and allow for processes and resources that encourage people to accept change when it intends to introduce changes to the way people work. It should look at the proposed changes from the users' perspective to understand how much time and effort will be required to bring about the desired change, where the inhibitions of the users may lie, and how their fears may be overcome. The organisation also needs to clarify the purpose of the proposed change, so that users don't have false hopes about the effect of the changes. Especially so, in the case of government organisations, which are traditionally regarded as risk-averse, and where staff may have the feeling that using wikis to work with the public may result in their standpoint coming under threat.

Some valuable lessons on mitigating risk have emerged from the interviews with respondents. The following measures can be considered for use by other government organisations who would like to deploy wikis in the future: 
- identify the target group and offer membership by invitation to them; for others who wish to join, ascertain identity and purpose;

- prepare a set of terms and conditions (taking the help of Legal and Communications staff in the organisation) for membership to the wiki;

- stipulate that would-be users register to gain access to the wiki and edit content;

- stipulate that users log on using their real name;

- include among the terms the condition that members of the wiki should obtain permission of a contributor before making use of his/ her posting elsewhere in any other context;

- $\quad$ state on the home page of the wiki that it may be monitored and moderated;

- inform would-be members that the contents of the wiki may be made available in response to requests made under the Official Information Act;

- enforce a lock-out after 5 failed attempts to logon;

- test the wiki while trialing it to see if it can be hacked;

- in case of attacks by vandals, consider taking the wiki offline for some time to deter their efforts; in case of persistent attempts to attack by vandals, have the wiki administrator block the IP addresses of the attackers. 


\section{Chapter 9: Wiki Usage: Barriers and Facilitation}

Chapter 7 looked at technical constraints that respondents have encountered while deploying a wiki. This chapter investigates non-technical barriers that respondents feel their stakeholders may have faced in using the wikis. It then considers the steps that respondents and their organisations had taken to facilitate the use of the wikis by stakeholders.

\subsection{Non-technical barriers}

The question on non-technological barriers that respondents thought stakeholders had encountered in using a wiki evoked a wide range of answers.

R6 thought that there was a lack of general awareness about wikis, while R3 broached the issue of trust that citizens may have in their government if they are required to log on in order to contribute to a wiki.

R2 felt that people may not necessarily want to post online, for which there could be various reasons:

(a) a fear of engaging, brought about by self-doubt about one's knowledge — or even a sense of whether one is 'allowed to' post one's views;

(b) not having the time, and caring enough about the issue to post (R4 also thought that lack of time could be a constraint for people); 
(c) not knowing how to post;

(d) the effort required to learn how to use wiki language, and working in a wiki environment (a factor that R4 also considered as a barrier);

A couple of other issues that emerged related to the problems of perception of a wiki by stakeholders, and the organisation and management of information.

\subsubsection{Perception of a wiki by stakeholders}

According to R6, there was a perception among stakeholders that the use of a wiki didn't appear to be seen as a legitimate way to consult with wide groups of people. R7 added that people unfamiliar with wiki technology or the casual Web 2.0 interface were sceptical of its value-adding ability to move a discussion forward.

R6 felt that stakeholders didn't necessarily see the direct benefits of being able to cocreate content in real time, while R7 said that not having a clear view of the end product would seem a barrier to stakeholders in their use of a wiki.

\subsubsection{Organisation and management of information}

R4 said that there were too many channels of information for people already, and that one had to be disciplined enough to check a wiki regularly for changes. A way of getting around this problem was to set up one's watchlist in the wiki so that any changes in the wiki pages of interest would be notified by email to the individual.

According to R5, information management becomes a problem without a clear structure for wiki pages that are created, since wiki software enables people to create 
wiki pages quite easily. R5 also felt that finding information could be frustrating when people tag using taxonomy/ folksonomy without a shared vision, given that different people view the same information in different ways.

Finally, a couple of other issues that emerged related to the suitability of wikis for organisations wanting to convey their views to a government department, and organisational culture as a barrier to the use of wikis.

R8 felt that wikis would not work for organisations that wish to make a submission to a government department, as they would like to have a well-reasoned point-by-point response to policy proposals — instead of a web page that any user could edit.

According to R10, a wiki runs contrary to the traditional way in which government employees have worked, i.e., individually, then through a system of peer review, and finally up the chain of superiors. Real-time co-creation of documents in a semi-public manner is in its infancy, and public sector employees have not adjusted to the idea of connection and co-creation.

\subsection{Facilitating the use of wikis by stakeholders}

The means employed by organisations to facilitate the use of wikis by their stakeholders can be grouped under the following themes:

\subsubsection{Promotion and training}

While R1 said that Wiki 1 had been advertised on the Public Sector Intranet, R3 mentioned that they had used word-of-mouth and pre-release of the wiki to users as 
promotional measures. R2 said that they had held a meeting to demonstrate the wiki to users.

R4 said that they had organised a couple of training sessions for Wiki 2, and had also offered individual hands-on training to users.

\subsubsection{Help and guidance information}

R2 had said that Help information was available on the wiki for users, and R10 reported that they had adapted the Help section from different MediaWiki wikis on the Internet, making it specific to the wiki which included it - i.e., Wiki 1 or Wiki 2. R10 also mentioned that Wiki 2 provided a link to the Helpdesk, in case users needed one-on-one support.

R6 mentioned that Wiki 3 included a How-To section that familiarised people with using the wiki, and R8 said that they had modified guidance available on government wikis overseas to provide instructions to users on using the wiki.

A couple of innovative means used were complementing the Help file with screencaptured movies (as R10 mentioned), and providing a Sandbox on the site for novice users to get a feel of using the wiki without actually impacting on the wiki itself (as R6 and R8 mentioned).

\subsubsection{Customising the wiki}

R9 said that Wiki 1 and Wiki 2 were highly customised so that the content of the home page would provide a quick idea of the wiki's purpose, as well as easy access to sections within the wiki. R9 also said that in the case of Wiki 1, there was some 
simplification of the default MediaWiki skin, and use of icons, images, etc., to show what pages could be edited and what couldn't, so as to simplify the whole experience for users.

\subsection{Discussion}

The barriers recounted above go well beyond those discussed by Guy (2006), and provide a broad range of reasons for users to shy away from a wiki. It is vital to the success of a wiki for the organisation to consider, well in advance, some of the reservations that members of the target audience may have about making use of the wiki - and to ensure that these issues are addressed before the wiki is deployed.

Some of the barriers revolve around the individual user, e.g., a fear of engaging, or not having the time/ caring enough to contribute. People respond positively to change when they are shown how the change can benefit them directly — or under the influence of their peers. The team responsible for deploying a wiki must find ways to demonstrate how the use of the wiki can make the work of the target audience easier. People do find time to do the things that they really want to do, and people are able to learn what is required when it is presented in bite-sized chunks.

The point about a wiki's rather casual interface leaving users unimpressed is understandable. The wiki's home page can be made to appear more credible by the inclusion of the organisation's logo. After all, it was not so long ago during the transition from paper documents to the computer screen that websites were regarded with a trace of suspicion by the public; yet today, people are comfortable even with transacting business using a mobile phone. Bedding down change takes time, and a 
critical mass of users also needs time to grow. People's perceptions change when confronted by the weight of numbers, but the numbers need to be shown the advantages that come with the change. As R7 has indicated, showing users how their contribution shapes the product can be a powerful motivator.

Ease of navigation in a wiki is of vital importance to the uninitiated. Klobas (2006) recommends providing a navigation guide on the homepage, or through a sidebar, or both, so as to make it easy for users to find their way around the wiki. Klobas advises including the following key links in the navigation guide — user guides, style guides, categories, and the sandbox.

R8's point about wikis being unsuitable for organisations that wish to make a formal submission to a government agency is interesting. However, that is hardly the purpose of a wiki; the well-established practice of sending submissions by post/ online can continue to serve the purpose of collecting submissions online. Wikis, after all, have been designed with the co-creation of content in mind.

What is of interest is R10's point about wiki practice being at odds with the way that government has traditionally worked. Government organisations are naturally hierarchic and tend to have a top-down style of management. It is therefore advisable to follow the advice offered by Fichter and Wisniewski (2008), i.e., find a champion. Government employees are less reluctant to change when superiors lead the way; selling the idea to a senior member of staff is the key to getting others to follow. Then again, with younger people entering the workforce, the use of tools such as wikis will continue to grow, since these are the tools of a new generation of workers. 
Klobas (2006) covers some of the ideas that have emerged from interviews with respondents on the steps that they had taken to facilitate the use of wikis by their stakeholders — ideas such as providing a sandbox, or guidelines on using the wiki. In fact, Klobas advises providing more detailed documentation (p.194), including:

- a statement of purpose;

- information about the wiki founder(s) and contact details;

- documentation of policies and other rules and guidelines (including information about any categorisation scheme adopted);

- help for new users

A couple of interesting ideas that respondents have mentioned are the use of screencaptured movies to help users learn how to use a wiki (R10), and the use of icons and images to show which pages can be edited, and which can't (R9). Needless to say, anything that helps novice users find their way will only serve to attract new users as well. While promotional efforts can capture the initial interest of people, it is the quality of training and documentation, ease of navigation around the wiki, and the usefulness of content in the wiki that contribute to retaining the interest of users. 


\section{Chapter 10: Using Wikis: Other Issues}

This final chapter on research findings reports on the answers provided by respondents when asked if they would like to comment on any other issue not covered during the course of the interview. The responses of participants reflect the perspectives of the individuals concerned. The comments were both positive and negative, and there were few common themes. However, a number of pertinent issues were raised.

\subsection{Various issues}

R1 was concerned about making rich-media content accessible to all users (e.g., the blind, and those working behind government firewalls), as government starts using such applications.

R5 found it frustrating to see content being created in yet another repository. R5 also thought that the selection process of a tool should be rigorous. R5 didn't consider wikis to be a panacea for collaboration/ information management, or that they would transform government, but thought that the behaviour and culture that enables wikis to be useful is what's really important.

$\mathrm{R} 4$ was interested in solutions to encourage the uptake of a wiki space by users. One of R4's concerns was dealing with the limitations of the tool/ platform, e.g., inability to upload certain formats (such as a calendar) easily to a wiki space. 
On the other hand, R10 was optimistic about the scope of innovation in the opensource community, and felt that the biggest limitation in MediaWiki appeared to be the imagination of the user - given its flexibility, and the fact that a number of people in the open-source community have developed a range of useful extensions to MediaWiki.

Another of R4's concerns was dealing with cultural and process changes in a business unit as a result of introducing a Web 2.0 tool. R9 felt that it was important to reassure people that wikis weren't the only way to interact, going forward.

R8 didn't consider wikis to be new, or that they even measured up to Web 2.0 status. What was new, in R8's opinion, was that government agencies were brave enough to use wikis.

R4 touched upon the spirit of experimentation in New Zealand's public sector organisations that have experimented with wikis, remarking that recognising — as a government agency - that risks are there in using Web 2.0 tools, managing the risks, and making progress in an innovative way can be interesting.

Alluding to Wiki 3, R6 commented on the overwhelming positive feedback from international commentators; R7, however, thought that the novelty in content — as opposed to the technology itself — was responsible for the success of the wiki. 
R9 was of the opinion that in many ways, wikis encourage good responsive practice — which fits very well with the State Services Commission's development goals. R9 felt that the challenge lay for government to meet this model of change.

\subsection{Discussion}

Being a semi-structured interview, respondents were deliberately given the opportunity through this last question to speak about anything that they felt was germane to the subject but had not been covered in the course of the interview. While the issues raised are fairly wide-ranging, it must be remembered that these are concerns articulated by people who have had first-hand experience of working with wikis from the planning stage right through to deployment, and that their words may be useful to those in the public sector considering the use of wikis in the future.

Dellow (2008) refers to R1's concern about rich-media content becoming increasingly available through Web 2.0 applications, albeit from the perspective of the Web's capacity to carry the surge in data being transferred across it. R1's concern was about accessibility, given that government employees usually access the Web from behind the corporate firewall. It would be reasonable to assume that once public sector employees start asking their IT staff to make such content available to them, the necessary modifications to the system will be made, particularly if the source is a trusted one, i.e., another government agency.

While R4's frustration at the creation of yet another repository for data is understandable, it underscores the importance of tool selection. A wiki that can export 
data as XML files — or even as PDF files — may be the way to go (other factors being equal).

Both R4 and R5 share a concern about the importance of cultural changes; while the former is concerned with managing the change, the latter is concerned with ensuring that the changes are bedded down. In practice, changes are successful only when they are accepted by a majority of staff and are, over the course of time, regarded as business-as-usual. And as R9 has observed, staff need to be reassured that the change isn't threatening.

R4's concern about the limitations of the tool may diminish over time because, as R10 says, if someone hasn't already created the extension to MediaWiki that is sought, it is only a matter of time before someone else does. Therein lies the advantage of opensource software - in the sheer numbers that make up the community of users and developers.

Before ending this chapter, it is worth considering how wikis and governments have come together. As R8 has said, wikis are not new (the wiki was invented in 1995); what is new is that government agencies are brave enough to use them. Perhaps nothing has emphasised the importance of government agencies sharing information among themselves as the destruction brought about by terrorist attacks on the USA on September 11th, 2001. In an unrelated development, Wikipedia, the encyclopaedia based on wikis, was launched in January 2001. By the time the Madrid bombings and the London bombings had taken place in March 2004 and July 2005 respectively, Wikipedia had become one of the most popular reference works in the world. 
Governments that were looking for a tool for their intelligence agencies to share information appear to have noticed the potential of the wiki to meet their purpose; hence, the launch of Intellipedia and Diplopedia in the USA. Other governments seem to have realised that the wiki had a lot to offer even in less critical roles. New Zealand is quite possibly a trend-setter in terms of using wikis for government organisations to collaborate with their stakeholders - both within government and outside of government. R4 has therefore lauded this spirit of experimentation that is present in New Zealand's public sector, while R9 has pointed out how wikis are a good fit with the State Services Commission's development goals. The challenge, as R9 says, lies in government meeting the model of change that wikis present. 


\section{Chapter 11: Conclusion}

I undertook this study because I was interested in learning how government organisations could make use of Web 2.0 tools — such as the wiki — to enhance engagement with their stakeholders. Technology had delivered; the question now was: is government ready to use the technology? Not much had been written on the subject of wiki use by government organisations, which, coupled with the fact that certain government organisations had already started making use of such tools, made it an interesting topic for research. I am glad I undertook this study, for I have learnt much from the insights of my participants.

From reading the literature, I was aware of the advantages of a wiki. I learnt something about the circumstances under which a wiki might be the tool of choice for government organisations: the fact that it can be accessed through the Web extends its reach to any place that has an Internet connection. It is comparatively easy to use, easy to set up, and relatively inexpensive; it is thus a useful tool to have should a government organisation wish to use it in consulting a wide range of people beyond its usual group of stakeholders - assuming, of course, that these stakeholders are netsavvy.

In terms of introducing such a tool to novices, it seems that the best approach is one that doesn't seem intimidating to users. Users need to be reassured that the wiki is a tool that supplements existing channels of communication, and that it doesn't replace those channels. Users will be more amenable to accepting it if it is used in a process that they are already familiar with, and its value can be established by making it a 
centralised repository for information that users need. In order to help users make the best possible use of a wiki, a communications strategy needs to be developed before a wiki is deployed. Such a strategy must identify the target groups of users, and consider ways to attract their attention, and retain their interest. The basis of the Web 2.0 world is the community, and a lot of effort must go into sustaining and developing the community by those who deploy the wiki. A truism in the Web 2.0 world is that if the user's experience of the tool is pleasant, the news can spread very quickly; the converse, of course, is equally true.

With regard to constraints in using such a tool, one issue that really stands out for me is the dilemma that government organisations might face: how does one strike a balance between hackers and vandals who might find a government wiki to be a particularly appealing target, and the need to establish and maintain trust within the community of users in keeping with the spirit of Web 2.0 software? That is, of course, from the perspective of a wiki administrator/ moderator. However, from the user's perspective, there is also the matter about trust in government. Given the government's need to authenticate users and verify their identity (if only to protect the community of users from hackers and vandals), how comfortable might a user be with disclosing his/ her actual identity to a government organisation simply in order to use the wiki? It appears that those deploying the wiki might need to pay particular attention to reassuring users about the security of personal information that they provide.

Interviewing the respondents opened my eyes to just how resource-hungry a Web 2.0 application such as a wiki can be. A government organisation that deploys such a tool 
needs to be prepared that it has more than adequate resources in terms of staff strength to be able to provide the monitoring, moderating and managing the online community that is part of deploying such a tool. The online world is active $24 / 7$, and does not care much for the hours that a government office maintains. Then again, government officials involved in moderating a wiki might feel the "obligation to action" (as one respondent has termed it) because of the instantaneous and public nature of wiki interactions. On the other hand, it is this transparency of a wiki that could help prevent issues from slipping through the cracks, as everything is out there for the community of users to see.

For government organisations, there are a couple of important issues to consider that have been mentioned by respondents. The first is the inherent contradiction between the wiki practice of allowing users to modify and shape content, and the risk-averse nature of a typical government organisation, which would prefer not to have outsiders meddling with its policies. Until this attitude changes, such an organisation is possibly not ready to use a wiki to engage with its stakeholders. The second issue is more fundamental to the working style of a typical government official. As a respondent has pointed out, government organisations are hierarchical structures, where an individual's work is reviewed by his/ her superiors before moving further up the chain towards its eventual destination. Wikis, on the other hand, can flatten hierarchical structures. Government officials need to be honest with themselves and decide if they are actually ready to embrace a new style of working, where content is created in collaboration with others. 
With younger people (who are used to the Web 2.0 world) joining the ranks of government, I an optimistic about growth in the use of such tools; however, it is for government organisations to judge if they are ready to make the best possible use of these tools.

$[16,961$ words $]$ 


\section{Bibliography}

Cabinet Office (2007). The Government's response to 'The power of information: An independent review by Ed Mayo and Tom Steinberg' [White paper]. Retrieved February 25, 2009 from the Cabinet Office website: http://www.cabinetoffice.gov.uk/strategy/publications.aspx

Cabinet Office (2008). Participation online: Guidance for civil servants [White paper]. Retrieved February 25, 2009 from the Civil Service website: http://beta.civilservice.gov.uk/news/2008/June/Online-Participation.aspx

Chen, P. (2007). Electronic engagement: A guide for public sector managers. Canberra: ANU E Press.

Cook, N. (2008). Enterprise 2.0: How social software will change the future of work. Hampshire, UK: Gower Publishing Ltd.

Cresswell, J.W. (2003). Research design: Qualitative, quantitative, and mixed methods approaches $\left(2^{\text {nd }}\right.$ ed.). Thousand Oaks, California: Sage Publications.

Dellow, J. (2008). So is the Read/ Write Web a friend or foe to information management? Image \& Data Manager, July/ August, 17-18.

Eggers, W. (2005). Government 2.0: Using technology to improve education, cut red tape, reduce gridlock, and enhance democracy. Lanham, MD: Rowman \& Littlefield Publishers, Inc.

Fichter, D. \& Wisniewski, J. (2008). Wiki while you work. Online, 32(3), 55-57.

Garson, G.D. (2006). Public information technology and e-governance: Managing the virtual state. Sudbury, MA: Jones and Bartlett, Publishers. 
Gorman, G.E. \& Clayton, P., with contributions from Rice-Lively, M.L., and Gorman, L. (1997). Qualitative research for the information professional: A practical handbook. London: Library Association Publishing.

Guy, M. (2006, October). Wiki or won't he? A tale of public sector wikis [Online exclusive]. Ariadne, 49. Retrieved February 4, 2009 from http://www.ariadne.ac.uk/issue49/guy/

Hernon, P. \& Cullen, R. (2006). Advancing E-government. In Hernon, P., Cullen, R. \& Relyea, H.C. (Ed.), Comparative perspectives on E-government: Serving today and building for tomorrow (pp.349-367). Lanham, MD: The Scarecrow Press, Inc.

Is Web 2.0 safe? (2007). New Zealand PC World, August, 22-23.

Jespersen, D.R. \& Boye, J. (2008). Untangling enterprise wikis. EContent, 31(9), 3034.

Klobas, J., with additional contributions from Beesley, A., Hlynsdottir, K.O., Marlia, M., Mitchell, P., and Paquet, S. (2006). Wikis as information sources. In J. Klobas. Wikis: Tools for information work and collaboration (pp. 35-61). Oxford: Chandos Publishing.

Laningham, S. (Podcast Editor). (2006). developerWorks Interviews: Tim BernersLee [Transcript of the interview]. In IBM's developerWorks Interviews podcast series. Recorded on 28 July 2006. Transcript retrieved February 27, 2009 from the developerWorks website at: http://www.ibm.com/developerworks/podcast/dwi/cmint082206.txt

Leedy, P.D. \& Ormrod, J.E. (2001). Practical research: Planning and design $\left(7^{\text {th }}\right.$ ed.). Upper Saddle River, New Jersey: Merrill Prentice Hall. 
Lenhart, A. (2009). Adults and social network websites. Retrieved January 20, 2009 from the Pew Internet and American Life Project website:

http://www.pewinternet.org/pdfs/PIP_Adult_social_networking_data_memo_FINAL .pdf

Manchester, A. (2007). How to use social media to engage employees. London: Melcrum Publishing.

Mayo, E., \& Steinberg, T. (2007). The power of information: An independent review by Ed Mayo and Tom Steinberg. Retrieved February 25, 2009 from the Cabinet Office website: http://www.cabinetoffice.gov.uk/strategy/publications.aspx

Millar, L. (2004). Networking government: E-government in New Zealand. Public Sector, 27(4), 2-7.

Mulgan, G., Steinberg, T., \& Salem, O. (2005). Wide open: Open source methods and their future potential. London: Demos, 2005.

National Research Council. (2002). Information technology, research, innovation, and e-government. Washington, D.C.: National Academy Press.

Noveck, B.S. (2008, Winter). Wiki-government: How open-source technology can make government decision-making more expert and more democratic [Online exclusive]. Democracy: A journal of ideas, 7. Retrieved September 10, 2008 from www.democracyjournal.org/article.php?ID $=6570$

O’Reilly, T. (2005). Web 2.0: Compact definition? Retrieved March 14, 2009, from the O’Reilly Radar blog at http://radar.oreilly.com/archives/2005/10/web-20compact-definition.html

Organisation for Economic Co-operation and Development. (2005). E-government for better government. Paris: Author. 
Organisation for Economic Co-operation and Development. (2007). Participative Web and user-created content: Web 2.0, wikis and social networking. Paris: Author.

Organisation for Economic Co-operation and Development. (2007, 31 January). Social and economic factors shaping the future of the Internet: Workshop proceedings. Washington. D.C.

State Services Commission. (2004). Achieving e-government 2004: A report on progress towards the New Zealand e-government strategy. Wellington: Author.

State Services Commission. (2005). E-awareness survey 2005: A survey of New Zealand e-government initiatives. Wellington: Author.

State Services Commission. (2006). Enabling transformation: A strategy for egovernment 2006. Retrieved September 10, 2007 from the State Services Commission website: http://www.e.govt.nz/about-egovt/strategy/nov$\underline{2006 / \text { strat } 9 . h t m l}$

Oxford English Dictionary Online. (2009). Retrieved February 27, 2009, from the Oxford English Dictionary Online database.

State Services Commission. (n.d.). Glossary built into the website of the State Services Commission at http://www.ssc.govt.nz/display/home.asp ; definitions appear in pop-up boxes on clicking search results obtained through the website's own search engine.

Symantec. (2008). Internet Security Threat Report Volume XIII. Retrieved March 1, 2009 from the Symantec website: http://www.symantec.com/business/theme.jsp?themeid=threatreport Tapscott, D., \& Williams, A.D. (2006). Wikinomics: How mass collaboration changes everything. London: Atlantic Books. 
The Economist. (2008, 16 February). The electronic bureaucrat: A special report on technology and government. The Economist, p.19.

Tonkin, E. (2005). Making the case for a wiki [Online exclusive]. Ariadne, 42.

Retrieved February 4, 2009 from http://www.ariadne.ac.uk/issue42/tonkin/

Vossen, G., \& Hagemann, S. (2007). Unleashing Web 2.0: From concepts to creativity. San Francisco: Morgan Kaufmann. 


\title{
Appendix A: Sample Permission Letter
}

\author{
Wellington
}

[Date]

\begin{abstract}
[Name]
[Address]

Dear [Name],

I am writing to seek your permission to interview selected members of your staff for a research project that I am undertaking as part of a Masters degree in Library and Information Management at Victoria University of Wellington. My research project will examine the ways in which New Zealand's central government organisations can use Web 2.0 applications to collaborate with their stakeholders. It is expected that the results of this study will help officials in other government organisations to gain a better understanding of the benefits, the technological constraints, the pitfalls and the barriers that they might have to face. The School of Information Management Human Ethics Committee, Victoria University, has given this project ethical approval.
\end{abstract}

I would like to invite members of your staff involved in running wikis or providing technical support in maintaining wikis, as well as those who have provided advice on communications policies, to participate in this study. Participants will be requested to attend one-on-one faceto-face interviews that I would like to conduct at your organisation, after obtaining your approval to do so. I expect each interview to take approximately one hour. Participants will be provided with a guide comprising the interview questions in advance to help them prepare their response. Any participant having reservations about participating in this project is free to inform me of this and withdraw from the project at any time before 24 January 2008; all data from that participant will then be destroyed.

Responses from participants will form the basis of my research project, and will be put into a written report on a confidential basis; your organisation may, with your consent, be identified. No information identifying individual participants will be included in the research report or any publications resulting from this research, and responses will be grouped wherever appropriate. I will provide transcripts of the interview to the participants for verification and approval. At the end of the project, I will also send a summary of the research findings to all the participants. No one other than my supervisor, Brenda Chawner, or me will have access to the recordings of the interviews, the transcripts, or my notes. Recordings as well as transcripts and my notes will be retained for a year after completion of this project, and then destroyed. A copy of my research report will be submitted to the School of Information Management for marking, and another copy will be deposited in the University Library. I intend to submit the results of this project to academic/ professional journals for publication.

If you have any questions or would like to receive further information about this project, please contact me at kochunanan@student.vuw.ac.nz (mob: 021-1199941), or my supervisor, Brenda Chawner, at the School of Information Management at Victoria University, PO Box 600, Wellington (phone: 04-463 5780).

Kind regards,

(Anand Kochunny) 


\title{
Appendix B: Information Sheet
}

\section{Participant Information Sheet for a study on the use of Web 2.0 applications by New Zealand's central government organisations to collaborate with stakeholders}

\author{
Researcher: Anand Kochunny, School of Information Management, Victoria University of \\ Wellington.
}

I am a Masters student in Library and Information Management at Victoria University of Wellington. As part of this degree, I am undertaking a research project. The project I am undertaking will examine the ways in which New Zealand's central government organisations can use Web 2.0 applications to collaborate with their stakeholders by studying the experiences of those organisations that have already done so. It is expected that the results of this study will help officials in other government organisations to gain a better understanding of the benefits, the technological constraints, the pitfalls and the barriers that these organisations have faced. The School of Information Management Human Ethics Committee, Victoria University, has given this project ethical approval.

I am inviting New Zealand government officials involved in running wikis or providing technical support in maintaining wikis, as well as those of their colleagues who have provided advice on communications policies, to participate in this study. Participants will be requested to attend one-on-one face-to-face interviews that I will conduct at their place of work after obtaining approval from the authorities concerned. I expect each interview to take approximately one hour. Participants will be provided with a guide comprising the interview questions in advance to help them prepare their response. Any participant having reservations about participating in this project is free to inform me of this and withdraw from the project at any time before 24 January 2008; all data from that participant will then be destroyed.

Responses from participants will form the basis of my research project, and will be put into a written report on a confidential basis; the organisations that employ the participants may however, be identified. No information identifying individual participants will be included in the research report or any publications resulting from this research, and responses will be grouped wherever appropriate. I will provide transcripts of the interview to the participant for verification and approval. At the end of the project, I will also send a summary of the research findings to all the participants. No one other than my supervisor, Brenda Chawner, or me will have access to the recordings of the interviews, the transcripts, or my notes. Recordings as well as transcripts and my notes will be retained for a year after completion of this project, and then destroyed. A copy of my research report will be submitted to the School of Information Management for marking, and another copy will be deposited in the University Library. I intend to submit the results of this project to academic/ professional journals for publication.

If you have any questions or would like to receive further information about this project, please contact me at kochunanan@student.vuw.ac.nz (mob: 021-1199941), or my supervisor, Brenda Chawner, at the School of Information Management at Victoria University, PO Box 600, Wellington (phone: 04-463 5780). 


\section{Appendix C: Consent Form}

Title of project: Using Web 2.0 to collaborate with stakeholders: An exploratory study of central government organisations in New Zealand

I have been provided with adequate information relating to the nature and objectives of this research project. I have understood that information and have been given the opportunity to seek further clarification or explanations.

I agree to take part in this research

I understand that I may withdraw from this study at any time before 24 January 2008 without providing reasons; should I do so, any data I have provided will be destroyed upon my intimation to the researcher of my withdrawal from the study

I understand that while any information or opinions I provide will be kept confidential and reported only in an aggregated/ non-attributable form, the organisation that employs me may be identified.

I understand that I will have an opportunity to check the transcripts of the interview before publication

I understand that the final report resulting from this research project will be deposited in the Victoria University of Wellington Library, and that the results may be published in academic or professional journals and presented at conferences

I understand that the recordings of interviews and transcripts of the same, as well as researcher's notes, will be retained for a year after this research is completed, and then destroyed.

I would like to receive a summary of the results of this research when it is completed

Signed:

Date: 


\section{Appendix D: Interview Guide}

1. Why did your organisation decide to set up and maintain a wiki instead of a different application such as a shared workspace?

2. How was the decision to create a wiki taken, and what was your role in this decision-making process?

3. What are the benefits that your organisation has obtained from using a wiki to collaborate with your stakeholders?

4. What are the strategies that your organisation has developed to maximise the benefits of using a wiki for engaging with your stakeholders?

5. What were the technological constraints that your organisation faced in implementing its decision to set up a wiki?

6. How did your organisation overcome these technological constraints?

7. In your opinion, what are the pitfalls that New Zealand's central government organisations face in using Web 2.0 applications such as wikis to collaborate with their stakeholders?

8. How did your organisation manage the risks from users associated with using social software such as a wiki?

9. From your experience, what are the barriers (other than technological) that your stakeholders have faced in using a wiki?

10. What were the means that your organisation employed to facilitate the use of wikis by your stakeholders?

11. From your experience of using a Web 2.0 application, would you like to mention anything else that has not been covered in this interview? 


\section{Appendix E: Sample of Primary Evidence Collected}

Q.1. Why did your organisation decide to set up and maintain a wiki instead of a different application such as a shared workspace?

\begin{tabular}{|l|l|l|l|l|l|l|l|l|l|l|}
\hline $\begin{array}{l}\text { Reasons for setting up } \\
\text { a wiki: }\end{array}$ & R1 & R2 & R3 & R4 & R5 & R6 & R7 & R8 & R9 & $\begin{array}{l}\text { R } \\
10\end{array}$ \\
\hline $\begin{array}{l}\text { Didn't need Government } \\
\text { Logon }\end{array}$ & $\sqrt{ }$ & & & & & & & & & \\
\hline $\begin{array}{l}\text { Made it easy technically, } \\
\text { and non-intimidating }\end{array}$ & $\sqrt{ }$ & & & & & & & & & \\
\hline $\begin{array}{l}\text { Right tool for the right } \\
\text { job }\end{array}$ & & $\sqrt{ }$ & & $\sqrt{ }$ & & & & & & \\
\hline $\begin{array}{l}\text { Enabled collaborative } \\
\text { creation }\end{array}$ & & $\sqrt{ }$ & & $\sqrt{ }$ & & & & & $\sqrt{ }$ & \\
\hline $\begin{array}{l}\text { Had prior experience of } \\
\text { using a wiki }\end{array}$ & & & & $\sqrt{ }$ & & & & & & $\sqrt{ }$ \\
\hline $\begin{array}{l}\text { To experiment with the } \\
\text { technology }\end{array}$ & & & & & $\sqrt{ }$ & & & & & \\
\hline $\begin{array}{l}\text { To determine the gaps in } \\
\text { the organisation's IM } \\
\text { process }\end{array}$ & & & & & $\sqrt{ }$ & & & & & \\
\hline $\begin{array}{l}\text { To share information } \\
\text { and keep it current }\end{array}$ & & & & & & & & & & $\sqrt{ }$ \\
\hline $\begin{array}{l}\text { To reach hard-to-hear } \\
\text { groups }\end{array}$ & & & & & & $\sqrt{ }$ & & & & \\
\hline Novelty factor & & & & & & $\sqrt{ }$ & & $\sqrt{ }$ & & \\
\hline $\begin{array}{l}\text { Ease of access, both } \\
\text { internally and externally }\end{array}$ & & & & & & & $\sqrt{ }$ & & & \\
\hline Easy to set up & & & & & & & & $\sqrt{ }$ & & \\
\hline
\end{tabular}

